\title{
Effects of hydrogen and primary air in a commercial partially-premixed atmospheric gas burner by means of optical and supervised machine learning techniques
}

\author{
Ana González-Espinosa ${ }^{a, c}$, Antonia Gil ${ }^{b, *}$, Lucía Royo-Pascual ${ }^{f}$, \\ Andrés Nueno ${ }^{a, e}$, Carlos Herce ${ }^{a, d}$ \\ ${ }^{a}$ CIRCE Institute (CIRCE Foundation - University of Zaragoza), Parque Empresarial Dinamiza Avenida Ranillas, 3D \\ $1^{a}$ Planta, 50018, Zaragoza, Spain \\ ${ }^{\mathrm{b}}$ Department of Mechanical Engineering, University of Zaragoza, Campus Rio Ebro, Building B. Maria de Luna s/n, \\ 50018, Zaragoza, Spain \\ c CIRCE Foundation, Parque Empresarial Dinamiza Avenida Ranillas, 3D $1^{a}$ Planta, 50018, Zaragoza, Spain \\ d ENEA - Italian National Agency for New Technologies, Energy and Sustainable Economic Development, Via \\ Anguillarese 301, 00123, Rome, Italy \\ e ENVIT - Advances Técnicos para el Medio Ambiente SL, Avda. de la Autonomía, $72^{\circ}$, 50003, Zaragoza, Spain \\ ${ }_{\mathrm{f}}^{\mathrm{E}}$ Electroingeniería industrial XCLC S.L. (Electroingenium), María Zambrano 31, Torre Oeste Planta 12 - Edif WTCZ, \\ 50018, Zaragoza, Spain
}

\section{H I G H L I G H T S}

- UV-VIS imaging and spectroscopy experimental tests in a commercial fuel burner

- Primary air-fuel ratio and $\mathrm{H}_{2}$ content have an impact in flame radical features

- A growing secondary nonpremixed cone develops when primary air decreases

- $\mathrm{OH}^{*}$ from non-premixed zone dominates imaging features and spectrometric data

- NOx emissions are predicted by UV-VIS imaging using LDA-NN

\section{A R T I C L E I N F O}

Article history:

Received 8 June 2020

Received in revised form

\section{G R A P H I C A L A B S T R A C T}

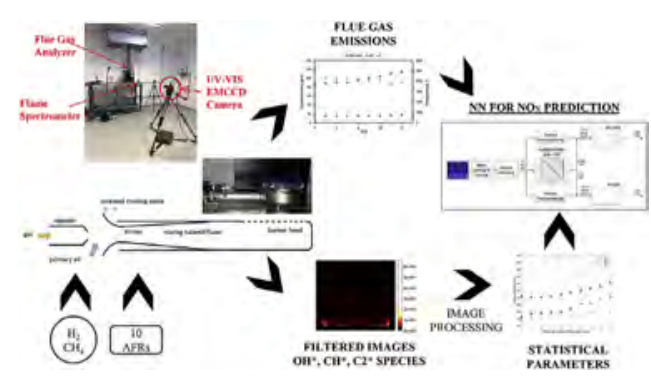

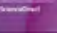


26 July 2020

Accepted 5 August 2020

Available online $\mathrm{xxx}$

Keywords:

Partially-premixed gas fuel burner

UV-VIS EMCCD

Predictive model

$\mathrm{NO}_{x}$

Supervised machine learning

Flame radical imaging features are extracted from a UV-VIS camera equipped with narrow-band optical filters. Radical image results agrees with spectrometric data, showing the relevance of the $\mathrm{OH}^{*}$ intensity radiation coming from the outer non-premixed zone. The double-cone flame structure is evident, showing a growing secondary non-premixed cone as the primary airfuel ratio is decreased. In addition, the direct relationship found between flame radical imaging features and $\mathrm{NO}_{x}$ emissions has been used to develop a predictive model by integrating classification techniques and neural networks. The research confirms UV-VIS chemiluminescence imaging techniques as powerful tools aimed at combustion monitoring, with huge prospects of being integrated within advanced emission control techniques for commercial burners.

๑ 2020 Hydrogen Energy Publications LLC. Published by Elsevier Ltd. All rights reserved.

\section{Introduction}

In recent years, industrial thermal processes are facing a complete transformation caused by the need of increase their reliability, flexibility and efficiency. The upcoming restrictive environmental and de-carbonizing framework in the near term has led to focus on renewable hydrogen-containing fuels. Burning $\mathrm{H}_{2}-\mathrm{CH}_{4}$ blends could decrease net $\mathrm{CO}_{2}$ emissions, but the effect is not simply proportional to $\mathrm{CH}_{4}$ reduction. Although both fuels share similar Wobbe indexes, they greatly differ in other relevant combustion properties, such as heating value, density or thermal diffusivity [1]. Hydrogen has lower density, lower volumetric heating value and lower stoichiometric air requirements that pure methane [2] and in case of burner retrofitting, burner adjustments are needed to keep similar thermal inputs [3]. As the $\mathrm{NO}_{x}$ formation is related with temperature and chemical kinetics which are largely influenced by fuel composition and equivalence ratio, the risk of increasing $\mathrm{NO}_{x}$ emissions has to be also taken into account.

Flame monitoring and control by optical devices have emerged as powerful techniques, even in harsh environments, thanks to the advances in instrumentation, digital data and control algorithms. The spontaneous emission from flames can be used, alone or combined with other methods to characterise a combustion mode. The chemiluminescence emitted by a hydrocarbon fuel flame, when acquired by optical devices such as spectrometers [4-8], or CCD cameras [9-16] provide valuable information regarding the combustion process, which has been experimentally related to heat release [17,18], equivalence ratio [19-21], temperature [22,23], pressure [24] and pollutant formation [25-27] in a variety of burners [28-30]. The captured information from flame images, after extracting relevant features, can be used to design predictive models aiming at combustion monitoring and control. Artificial intelligence techniques such as neural networks, fuzzy logic and pattern recognition and classification algorithms are increasingly been used to build grey models [31-34] aimed to emissions control.

In case of gaseous hydrocarbon fuels, the prompt and thermal mechanisms are the main contributors to $\mathrm{NO}_{x}$ formation which are mainly related to the radical species $\mathrm{OH}^{*}$ and $\mathrm{CH}^{*}$ generated in the flame front zone. Emission signals from these radicals, or their ratios have been used to predict $\mathrm{NO}_{x}$ emissions. For instance, Muruganandam et al. [35] used an active control loop in a natural gas premixed burner using the $\mathrm{OH}^{*}$ emission signal to minimise $\mathrm{NO}_{x}$. Artificial neural networks (ANN) have also been proposed in a partiallypremixed burner at lean conditions to predict $\mathrm{NO}_{x}$ from $\mathrm{OH}^{*}$ chemiluminescence imaging, including other experimental measurements such as flame temperature and air flow rate [26]. In this way, an algorithm based on ANNs was used in a Bunsen burner to predict the $\mathrm{NO}_{x}$ emissions taking into account flame radicals $\left(\mathrm{OH}^{*}, \mathrm{CH}^{*}\right.$ and $\mathrm{C}_{2}^{*}$ and $\left.\mathrm{CN}^{*}\right)$ ratios [36].

Although premixed and partially-premixed flames have been extensively studied for traditional hydrocarbon fuels, the application of visualization techniques to emission monitoring in commercial burners is less common. For instance, Ruao et al. [37], by extensive experimental testing on a $15 \mathrm{~kW}_{\text {th }}$ laboratory swirl burner, using propane and ethylene as fuels, found a strong correlation of $\mathrm{NO}_{x}$ emissions with $\mathrm{CH}+\mathrm{OH}$ radicals photometric data, using a UV-VIS ICCD camera and dedicated filters. Results showed that the $\mathrm{NO}_{x}$ formation was strongly dominated by the prompt (or Fenimore) mechanism which can be related with lower temperatures at these laboratory scale conditions.

Similar results were obtained in a Bunsen burner by Jeong et al. [21] who tested the effect of varying the air-fuel equivalence ratio on the radicals emission, with values ranging from 0.9 to 0.1 . Naha et al. [38] numerically studied the effect of using different fuels (methane and $n$-heptane) blended with hydrogen on $\mathrm{NO}_{x}$ emissions in counterflow partiallypremixed flames at air-fuel equivalence ratios of 0.62 and 0.5. They show that for methane flames, the decrease in the prompt NO due to hydrogen addition was balanced by the corresponding increase in the thermal NO, and the total NO was essentially unaffected by the hydrogen addition. Burbano et al. [39] achieved a reduction on $\mathrm{CO}$ emissions on an atmospheric residential burner for $\mathrm{CH}_{4}-\mathrm{H}_{2}$ blends when increasing $\mathrm{H}_{2} \%$ up to $15 \%$ in vol, who attributed to an increase in the $\mathrm{OH}^{*}$ radical promoting the $\mathrm{CO}$ oxidation to $\mathrm{CO}_{2}$ at an air-to-fuel ratio of 0.35 and $3 \mathrm{~kW}$ of thermal input.

The recent interest of injecting renewable hydrogen to the natural gas grid has recently promoted several studies dealing with the behaviour of hydrogen-methane blends in cooktop and oven burners (see for example, DeVries [40] and Zhao 
$[41,42])$. However, up to date, there is a need of further research dealing with the impact of increasing the hydrogen content of the fuel, specially on commercial burner performance and emissions. In addition, the impact of decreasing the air-fuel ratio in partially-premixed conditions is not fully addressed. Previous published studies have worked with airfuel equivalence ratios ranging from fuel-lean to fuel-rich conditions up to 0.71 , but few operate with lower air-fuel ratios, which is typical of partially premixed flames usually found in cooktop burners.

This paper deals with the performance assessment of a $10 \mathrm{~kW}_{\text {th }}$ commercial partially-premixed gas burner operating with methane and a blend of methane and hydrogen using optical and spectrometric techniques aimed at combustion monitoring. A UV-VIS EMCCD camera equipped with narrowband filters $\left(\mathrm{OH}^{*}, \mathrm{CH}^{*}\right.$ and $\left.\mathrm{C}_{2}^{*}\right)$ and a spectrometer were used for burner characterization at different fuels and air-fuel ratios.

Finally, the study ends with the development of a predictive $\mathrm{NO}_{x}$ model based on flame radical imaging. The model discriminates the type of gas and the primary air position (defined as a measure of the primary air-fuel ratio) and estimate $\mathrm{NO}_{x}$ emissions, using a classification algorithm and a neural network. Thus, it has been proved the feasibility of this model to be integrated in advanced control schemes such as model predictive control strategies, considered at present as powerful techniques to be implemented at larger scales.

\section{Methodology}

\section{Experimental and methods}

The experimental setup (Fig. 1) consists of a $10 \mathrm{~kW}_{\text {th }}$ crowntype commercial atmospheric gas fuel burner, fed by high pressure gas bottles (1). A two-stage decompression system reduces the gas pressure to the desired value. The first stage (2) reduces the fuel pressure from pressure bottle (maximum 200 bar-5 bar). The second one, located in the laboratory room (3) allows to fix the pressure output to the desired value, measured by a manometer located at the burner entry. A stable and secure burner operation was assured by an electro valve block equipped with a pressure regulator (4) and a flame sensing electrode. Finally, an extraction hood evacuates combustion gases by means of a vertical tube located $12 \mathrm{~cm}$ above the burner, in such a way that the flame remained visible for image camera acquisition, allowing the burner to work at ambient conditions.

Fig. 2 shows the gas burner (see also Table 1 for relevant dimensions). The primary air from the surroundings is aspirated through the injector by means of the Venturi effect. The air-fuel mixture is guided along the mixing tube to the circular burner head, where it is distributed and exits to the ambient through the orifices. The exit orifices are located at two different diameters, leading to multiple inner and outer flames.

Two gaseous fuels were tested, according to EN 437:2018 standard [43]: (1) pure methane (hereafter G20), and (2) a 23-77 vol\% mixture of hydrogen and methane, respectively (hereafter G222). The fuel gas pressure was maintained at a constant value of 17 mbar (g) for all tests.

The primary air aspirated by the Venturi is regulated by means of an air shutter (a movable piece at the air inlet), shown in detail in figure A.13, which was equipped with an external thread. Using a standard calliper, different positions (named hereafter as Primary Air Positions, PAP) were fixed by measuring the distance between the left part of the injector (chosen as the reference point) and the edge of the movable piece. Each position corresponds with a certain number of visible thread pitches (Table 2) where PAP 4 corresponds to leaner conditions than PAP 13.

The primary air is not usually measured in this type of atmospheric self-aerated commercial gas burners. Therefore, in order to estimate the primary air flow aspirated by the burner as function of the primary air position (PAP) and hence, the primary air-fuel equivalence ratio, a semi-empirical modelling approach was adopted, according to the work of Jones [44]. For the sake of conciseness, governing equations and results of the model are not included here, and are explained in full detail in Appendix B. Results of the primary air-to-fuel equivalence ratio lay in the fuel-rich region, i.e. 0.58-0.37 (for G20) and 0.62-0.39 (for G222) at PAP 7-13,

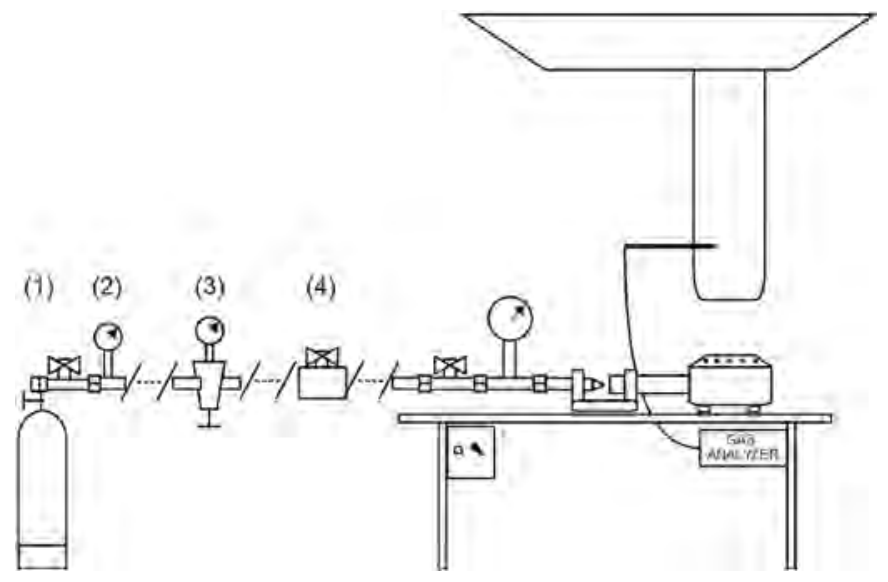

Fig. 1 - Test rig scheme. (1) Gas cylinder, (2) first decompression stage, (3) second decompression stage and (4) electro valve block. 


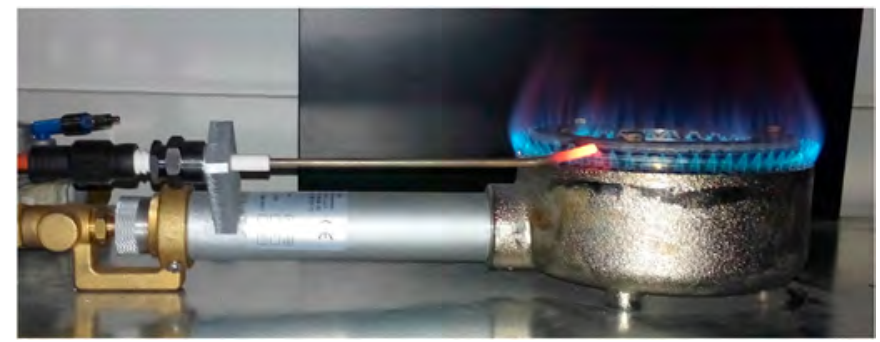

Fig. $2-10 \mathrm{~kW}_{\text {th }}$ crown-type atmospheric burner.

Table 1 - Main burner data.

\begin{tabular}{ll} 
Parameter & Value \\
\hline Injector diameter $D_{i}, \mathrm{~mm}$ & 2.4 \\
Throat diameter, $D_{t}, \mathrm{~mm}$ & 18 \\
Burner port diameter, $D_{p}, \mathrm{~mm}$ & 3 \\
External diameter, $\mathrm{mm}$ & 140 \\
Internal diameter, $\mathrm{mm}$ & 80 \\
Height, mm & 80 \\
Number of orifices & 64 (out) +24 (in) \\
\hline
\end{tabular}

Table 2 - Primary air position (PAP) of the air shutter (=No. of thread pitches) vs relative distance from the fuel injector orifice.

\begin{tabular}{lc} 
PAP & Relative distance, $\mathrm{mm}$ \\
\hline 4 & 15 \\
5 & 14 \\
6 & 13 \\
7 & 12 \\
8 & 11 \\
9 & 10 \\
10 & 9 \\
11 & 8 \\
12 & 7 \\
13 & 6 \\
\hline
\end{tabular}

respectively (see Table 3). Besides, this table presents the significant parameters of the nitrogen gas used for the modelling of the air entrainment flow. This fact implies, as expected, that the burner flames are of the partially-premixed type, and a relevant quantity must be taken as secondary air from the surroundings in order to achieve complete fuel combustion.
Flames remained stable and no flashback was detected during experiments. Only a small amount of soot occasionally appeared at the end of the operating period settled on the head burner for low air-fuel ratios. However, this fact does not affect the images taken from the camera since the visible radiation from soot particles is emitted at larger wavelengths. A clean procedure was developed in order to assure the repeatability of the experiments. When soot particles were detected, the burner was shut off, cooled down and cleaned. Thus, for the G20 case the cleaning stops were performed before PAP 9 and 12, whereas, for G222 the stops took place before PAP 7, 10 and 13. For each fuel gas, measurements started after 20 min from the ignition point at room temperature. This value was obtained as a representative time of stabilization after performing tests.

Figure A.14 shows a picture of the experimental setup. An Electron Multiplying Charge Coupled Device (EMCCD) camera (Raptor Photonics) with a $78 \mathrm{~mm}$-fixed focal length PentaxRicoh lens sensitive to the UV-VIS range was used for flame radical imaging characterization. The EMCCD camera, fixed on a robust tripod, was placed $193 \mathrm{~cm}$ away from the burner. Two black perpendicular panels were installed in order to provide a black image background.

Three narrow-band optical filters were used, corresponding to the emission of the radicals $\mathrm{OH}^{*}, \mathrm{CH}^{*}$ and $\mathrm{C}_{2}^{*}$, respectively: (1) $310 \pm 10 \mathrm{~nm},(2) 430 \pm 10 \mathrm{~nm}$ and (3) $515 \pm 10 \mathrm{~nm}$. The F-number and gain were optimised by preliminary testing and set to a value of 3.8 and 2600 , respectively, for all tests. Also, different exposure times were previously evaluated by additional testing, selecting $100 \mathrm{~ms}$ as the time that maximises exposure time without reaching image saturation.

The EMCCD camera captured a total amount of 342000 experimental flame images during the tests, which corresponds to 25 sequences of 228 pictures for each of the narrowband filters $\left(\mathrm{OH}^{*}, \mathrm{CH}^{*}\right.$ and $\left.\mathrm{C}_{2}^{*}\right), 10$ Primary Air positions (PAP

Table 3 - Main operation parameters of the tests. See appendix for more information.

\begin{tabular}{|c|c|c|c|}
\hline Parameter & G20 & G222 & $\mathrm{N}_{2}$ \\
\hline $\begin{array}{l}\text { Fuel gas composition, \%vol } \\
\text { Inlet gas pressure (mbar (g)) }\end{array}$ & $100 \% \mathrm{CH}_{4}$ & $\begin{array}{l}23-77 \% \mathrm{H}_{2}-\mathrm{CH}_{4} \\
17 \text { (all tests) }\end{array}$ & $100 \% \mathrm{~N}_{2}$ \\
\hline Fuel orifice Reynolds number, $R e_{i}$ & 8671 & 7833 & 7173 \\
\hline Wobbe index (high, $\mathrm{MJ} / \mathrm{Nm}^{3}$ ) & 53.40 & 50.40 & - \\
\hline Thermal input (HHV basis, kW) & 10.10 & 9.52 & - \\
\hline Relative fuel-air density & 0.55 & 0.44 & 0.97 \\
\hline Stoichiometric air-fuel ratio, $A F R_{\text {stoich }}$ & 9.48 & 7.85 & - \\
\hline Primary air-fuel ratio, R (PAP 7-13) & $5.46-3.50$ & $4.86-3.10$ & - \\
\hline Primary air-fuel equivalence ratio (PAP 7-13) & $0.58-0.37$ & $0.62-0.39$ & - \\
\hline
\end{tabular}


from 4 to 13) and 2 types of fuel gases (G222 and G20). The information was randomly split in order to avoid problems with the data selection and ensure consistency of the model. Repeatability of the tests was assured by anchoring the camera set-up to the floor during the whole experimental campaign. After every filter change refocusing was required to acquire sharpen flame images. The camera was fixed for each test in order to assure the same frame.

The captured raw flame images in TIFF format were pro-

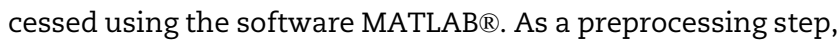
the electronic noise of the EMCCD camera was obtained and subtracted from the acquired images at the camera operational conditions. In a second stage, the images were cropped to avoid including irrelevant parts of the burner. A postprocessing script was developed to obtain relevant statistic parameters of the images, based on previous research $[9,10,13,14]$. Besides, a threshold binarization was used to obtain the flame areas. This technique converts a raw image into a binary image, based on a certain level previously optimised for the filters and fuel gases. Additionally, the mean of each statistical variable in the sequence of 228 images was computed. A total number of 25 sequences were recorded at each PAP.

Simultaneously to the EMCCD images and for comparative purposes, an extensive series of flame emission spectra were also acquired by means of a miniature portable spectrometer (Flame S, Ocean Optics), a linear silicon CCD array detector formed by 2048 pixels, able to detect the radiation emitted by the flame across the wavelength range 190-1100 nm. In order to identify the radiation generated by the flame root, the tip of the optical fibre $(\mathrm{NA}=0.22)$ was placed in a tripod at $14 \mathrm{~cm}$ from the burner head and at three different levels above the table surface: 7, 9 and $11 \mathrm{~cm}$. The optical fibre was connected to the spectrometer by a $50 \mu \mathrm{m}$ slit. For each condition, 100 spectra at $100 \mathrm{~ms}$ of integration time were acquired.

Finally, in order to find out a correlation between $\mathrm{NO}_{x}$ emissions and flame radical imaging, both measurements were registered simultaneously. Thus, the $\mathrm{NO}_{x}$ concentration $\left(\mathrm{NO}+\mathrm{NO}_{2}\right)$ in dry flue gases was measured by a flue gas analyser (MRU Air Fair Optima 7), equipped with electrochemical sensors which was connected to a probe introduced at the center of the exhaust system tube through an orifice located at $50.5 \mathrm{~cm}$ above the burner support. Also, $\mathrm{CO}$ and $\mathrm{O}_{2}$ concentrations were also registered with the same instrument during the tests. Measurements were taken at a frequency of $1 \mathrm{~Hz}$. Accuracy was $\pm 5 \mathrm{ppm}$ or $\pm 5 \%$ of the reading according to the instrument supplier. Data were synchronised to the camera imaging acquisitions in order to be able to correlate them with flue gas emissions. A total of $30-\mathrm{NO}_{x}$ measurements were averaged in order to have the same time frame average as in the case of the imaging system. Collected data were used to develop a model based on supervised machine learning techniques. All $\mathrm{NO}_{x}$ and $\mathrm{CO}$ measurements were normalised to $0 \% \mathrm{O}_{2}$ in volume basis using the reading of the $\mathrm{O}_{2}$ probe. Temperature measurements were taken with a $\mathrm{K}$ type-thermocouple placed on the exhaust conduct.

\section{NOx predictive model}

A general overview of the system block diagram is shown in Fig. 3. Two different supervised machine learning algorithms have been applied to estimate $\mathrm{NO}_{x}$ emissions from flame image radical features obtained from the EMCCD images in TIFF format. Firstly, a classification algorithm was used to categorise the data, according to the type of gas and primary air position and using the information derived from flame images. Secondly, using this information and radical imaging post-processed features, $\mathrm{NO}_{x}$ emissions were predicted with a neural network model trained with experimental data. A detailed description of each algorithm is further explained in Appendix C.

\section{Results and discussion}

\section{EMCCD image results}

Fig. 4 shows averaged false-coloured images for G222 and G20 obtained from tests using narrow-band filters installed in front of the EMCCD camera. RGB images are also shown for comparison. For conciseness, only the lowest and highest tested values are illustrated, corresponding to the highest

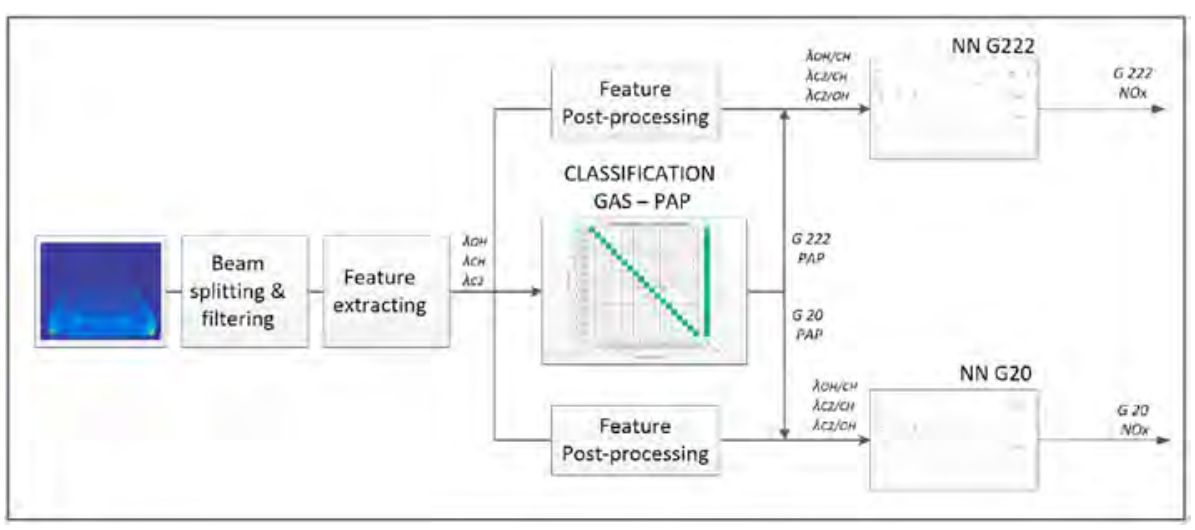

Fig. 3 - System block diagram for the prediction of $\mathrm{NO}_{x}$ emissions through flame radical imaging by supervised machine learning techniques. 


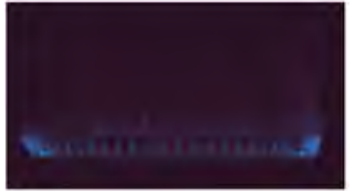

(a) G222-RGB

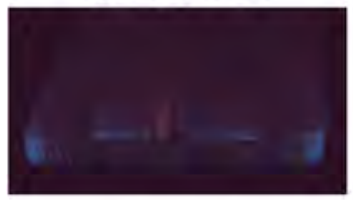

(e) G222-RGB

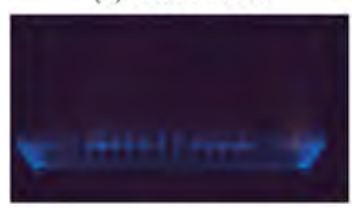

(i) G20-RGB

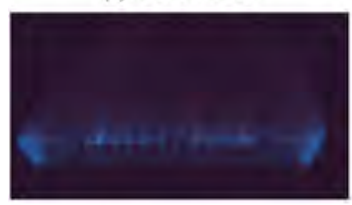

(m) G20-RGB

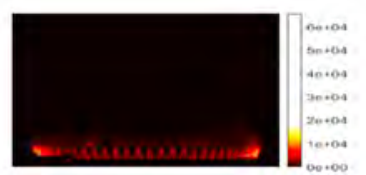

(b) $\mathrm{G} 222-\mathrm{OH}^{*}$ filter

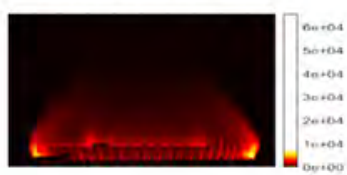

(f) $\mathrm{G}_{222-\mathrm{OH}^{*}}$ filter

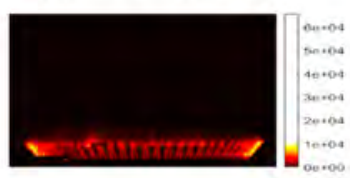

(j) $\mathrm{G} 20-\mathrm{OH}^{*}$ filter

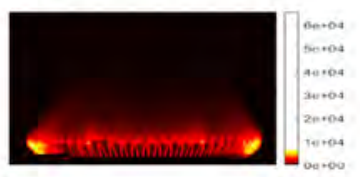

(n) $\mathrm{G} 20-\mathrm{OH}^{*}$ filter

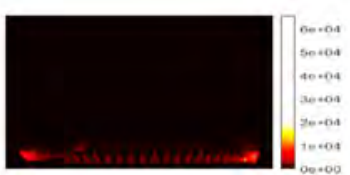

(c) G222-CH* filter

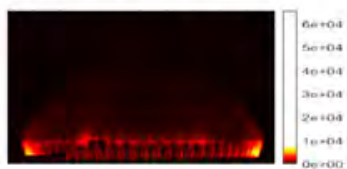

(g) $\mathrm{G} 222-\mathrm{CH}^{*}$ filter

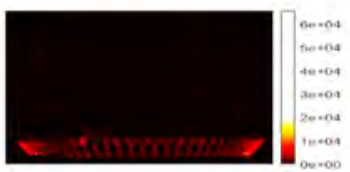

(k) G20-CH* filter

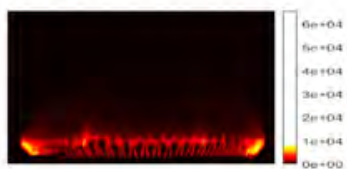

(o) G20-CH* filter

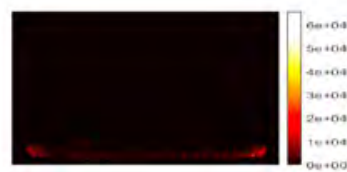

(d) G222-C2* filter

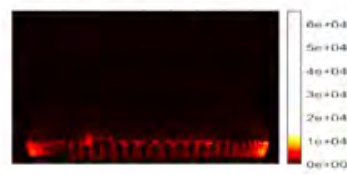

(h) G222-C2* filter

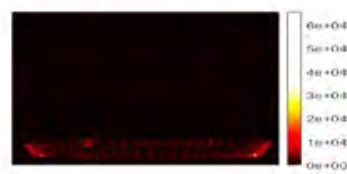

(1) G20-C2* filter

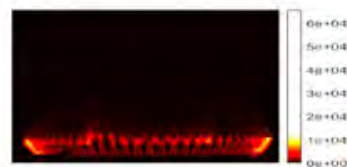

(p) G20-C2* filter

Fig. 4 - Instantaneous RGB and EMCCD images in false color scale at PAP 4 (a-d) and 13 (e-h) for $\mathrm{G}_{222}\left(23 \% \mathrm{H}_{2}-77 \% \mathrm{CH}_{4}\right)$ flames; at PAP $4(\mathrm{i}-\mathrm{l})$ and $13(\mathrm{~m}-\mathrm{p})$ for $\mathrm{G} 20\left(100 \% \mathrm{CH}_{4}\right)$ flames. (For interpretation of the references to colour in this figure legend, the reader is referred to the $\mathrm{Web}$ version of this article.)

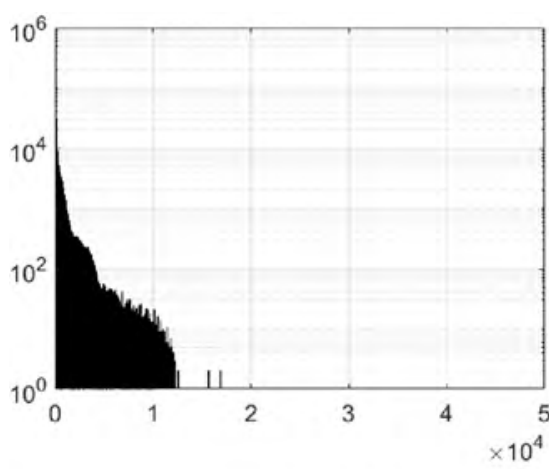

(a) $\mathrm{OH}^{*}$ filter PAP 4

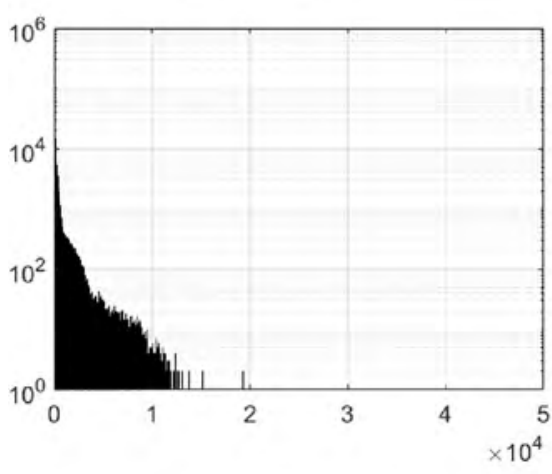

(c) $\mathrm{CH}^{*}$ filter PAP 4

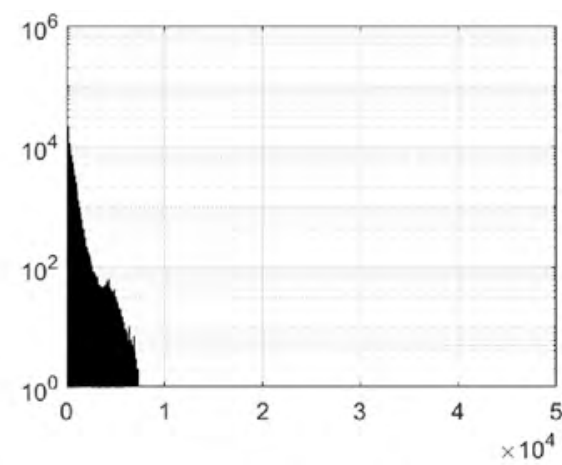

(b) $\mathrm{OH}^{*}$ filter PAP 13

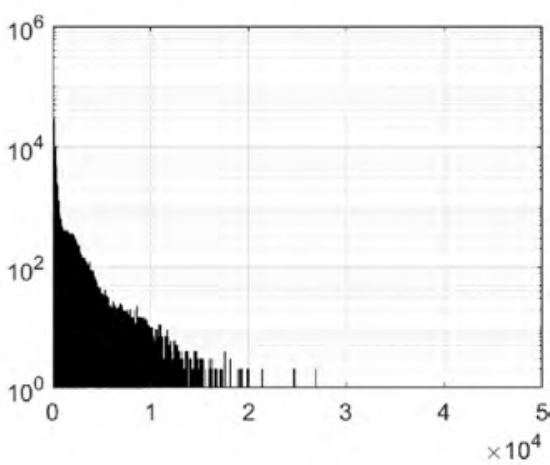

(d) $\mathrm{C}^{*}$ filter PAP 4

Fig. 5 - Examples of intensity image distribution of G222 flames. 
(PAP 4) and the lowest (PAP 13) primary air entry flow rate, respectively.

The double-cone flame structure, typical of partiallypremixed flames $([21,45])$ is developed. Two different zones can be clearly distinguished from examination of Fig. 4: (1) a premixed reaction zone close to the burner exit, and (2) an outer reaction zone where the unburnt gas mixture reacts with the surrounding air. Although the reduction of the primary air generates flames with lower values of maximum intensity (see for instance (b) and (f)), the image area with significant intensity increases, in particular for $\mathrm{OH}^{*}$ and $\mathrm{CH}^{*}$ images.

In the case of G222 (Fig. $4(\mathrm{a}-\mathrm{h})$ ), the flame seems to be cone-shaped for PAP $13(\mathrm{e}-\mathrm{h})$, while it seems to be triangleshaped for PAP 4 (a-d). Besides, the length of the inner cone increases when the primary air flow is reduced, in accordance with longer residence times needed to complete combustion. In consequence, for PAP 13, the flames generated in the inner orifices of the burner head can be more clearly observed behind the first line of flames.

According to the results presented in Fig. 4 (i-p), the shape and length of the pure methane flame (G20) does not substantially change when primary air-fuel ratio is decreased, in contrast to results for G222. The overall image mean intensity is higher when PAP is increased (lower primary air fuel ratio). The inner reaction zone is thinner and shorter for G222 images, as compared to the results of G20 flames, which exhibit longer reaction zones. Since the $\mathrm{H}_{2}$ concentration is higher for the G222 fuel, a slightly higher laminar burning velocity than pure methane is expected [46-48] and a decrease in both flame thickness and thickness of reaction zone [49], which results in shorter flames [39,40,50-53]. The presence of hydrogen affects the response of the flame to the stretch rate due to transport effects through the fuel Lewis number [2]. Moreover, images with the $\mathrm{OH}^{*}$ filter enable the visualization of a greater area of the secondary cone coming from the outer non-premixed flame, as compared to $\mathrm{CH}^{*}$ and $\mathrm{C}_{2}^{*}$ ones. The $\mathrm{OH}^{*}$ distribution can be observed in both reaction zones, whereas the generation of $C_{2}^{*}$ is mainly concentrated in the premixed inner flame reaction zone. The $\mathrm{CH}^{*}$ distribution can be also distinguished in both regions, although the corresponding to the premixed zone is more significant.

Fig. 5 shows some samples of the pixel intensity distribution obtained at different combustion conditions and species. In all cases, the highest frequencies appear at low intensity levels, which can be related to the greater area occupied by the background. Thus, the maximum of the distribution is observed at low levels. At a medium intensity level, the frequency decreases sharply which can be related with the flames whereas as intensity levels increase the frequency decreases smoothly.

In addition, Figs. 6 and 7 show results of averaged values of the statistical parameters computed from the images (mean, standard deviation, skewness and kurtosis) for each of the filters tested $\left(\mathrm{OH}^{*}\right.$ in blue diamond, $\mathrm{CH}^{*}$ in green square and $\mathrm{C}_{2}^{*}$ in red triangle) and fuel gas (G222, left; G20, right). Fig. 6 (a and b) shows average image mean intensity for (a) G222 and (b) G20 in CCD counts obtained from EMCCD images and narrow-

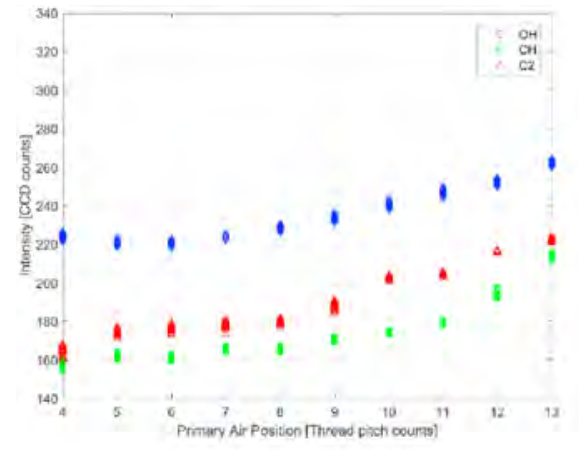

(a) G222 gas - mean

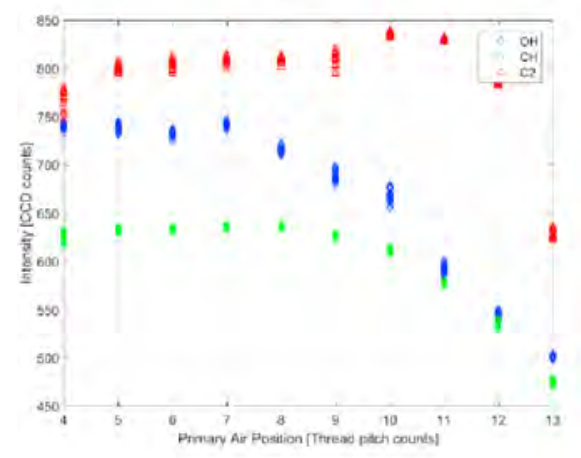

(c) G222 gas- std

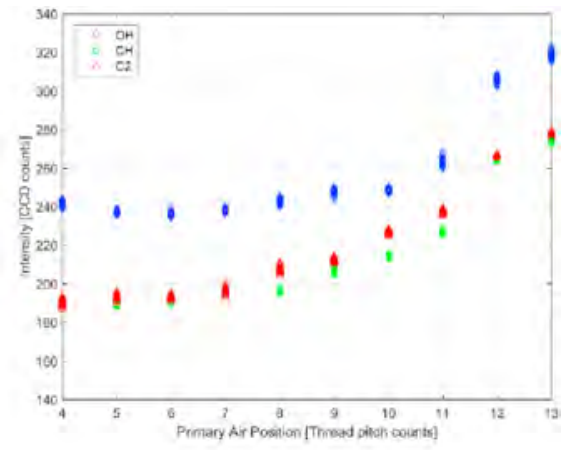

(b) G20 gas -mean

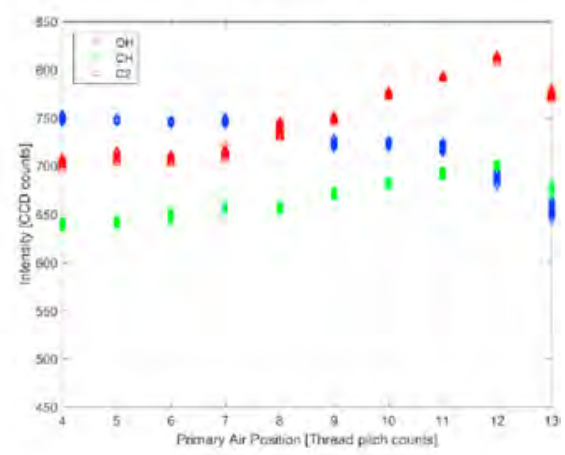

(d) G20 gas -std

Fig. 6 - Average image intensity mean (raw): (a) G222 gas, (b) G20 gas. Standard deviation (raw): (c) G222 gas, (d) G20 gas. 


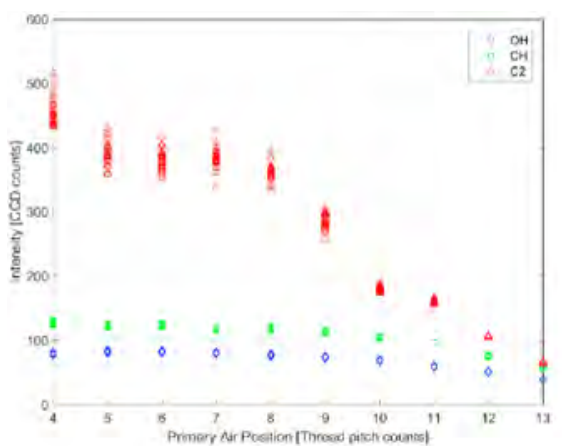

(a) G222 gas -kurt

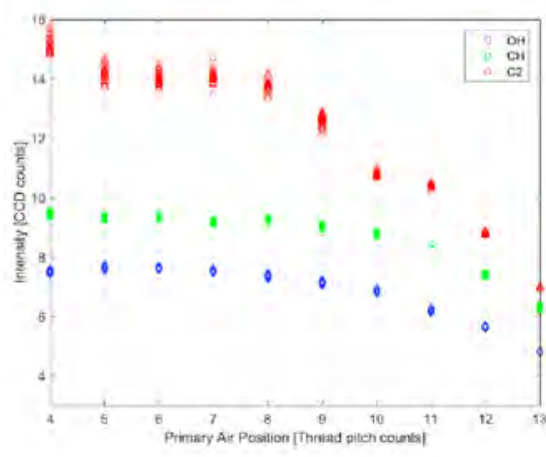

(c) G222 gas - skw

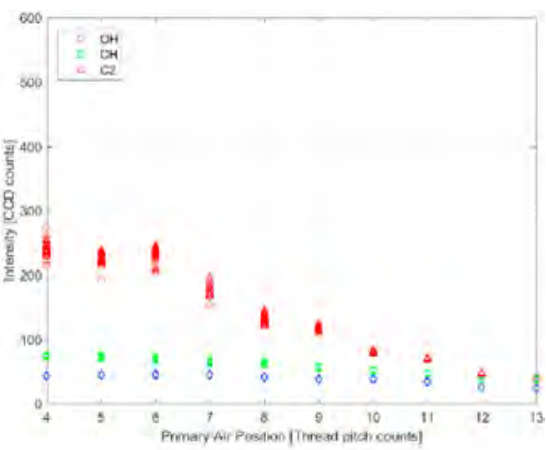

(b) G20 gas -kurt

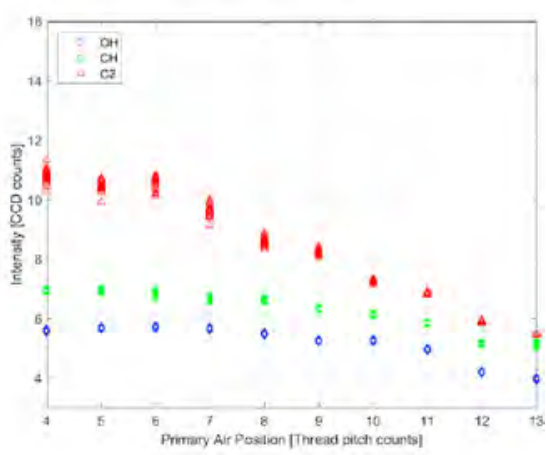

(d) G20 gas - skw

Fig. 7 - Average image intensity kurtosis (raw): (a) G222 gas, (b) G20 gas; Skewness (raw): (a) G222 gas, (b) G20 gas.

band optical filters using the methodology explained in section Experimental and methods. As shown in the figures, the greatest mean intensity corresponds to the $\mathrm{OH}^{*}$ filter, for both gases and all test conditions. Also, an upward trend of the mean intensity value when the primary air mass flow is reduced (lower PAP) can be clearly distinguished for all optical filters. Although the maximum intensity value is reached for the lower PAP, based on the coloured image values (Fig. 4), the overall intensity increases for higher PAP, which can be related to the contribution of a larger reaction zone generated at this condition. The reduction of the primary air promotes a higher distribution of the flame intensity.

The trend of the G20-OH* mean intensity (Fig. 6(b)) is nearly constant with PAP up to PAP 11, where suddenly increases. This effect has been identified for all filters. However, in case of G222 gas (Fig. 6(a)), the slope change is not detected. The image range intensity was not the same for G222 and G20, most probably due to the slight differences in thermal input rates (see Table 3). In addition, since the G222 fuel has relevant hydrogen content, the mean intensity difference between the $\mathrm{OH}^{*}$ and $\mathrm{CH}^{*}$ or $\mathrm{C}_{2}^{*}$ radicals is higher in the case of $\mathrm{G} 222$ than in G20 for all PAP [54].

Regarding standard deviation, similar trends were obtained for both fuels. This parameter can be related to the uniformity of the flame, where lower values reveal a high uniformity of the flame intensity distribution within the image, which means a lower difference between the extreme values. Fig. 6 (c and d) shows the results of the EMCCD camera averaged image standard deviation. In both fuels, the $C_{2}^{*}$ standard deviation seems to have a maximum value. It is produced in PAP 10 in the case of G222 and in PAP 12 in the case of G20. This effect may be in part caused by the aforementioned small differences in the thermal input. As PAP increases, the standard deviation decreases in the case of G222. In the case of G20, flame size differences between lower and higher PAP are lower than in the case of G222, and the flame size remain practically constant during the whole range of values tested. The standard deviation range is clearly higher than the average level of intensity. This is directly related to the huge differences between dark pixels and bright pixels in the lateral sides of the burner.

Kurtosis and skewness results obtained from the images are shown in Fig. 7. As the primary air is decreased, the trends are similar for both fuels tested. ${ }^{1}$ Values obtained from skewness indicate that the image intensity distribution is concentrated in lower values of intensity than the average, due to the low levels of intensity obtained in the recorded images.

According to the results shown in Fig. 7, the kurtosis decreases when PAP increases, particularly for $C_{2}^{*}$ radical. A higher uniformity of the intensity values implies a reduction on the extreme values of the histogram, which is reflected in a

${ }^{1}$ Kurtosis and skewness are descriptors of the shape of a statistical distribution. A distribution with positive kurtosis is called leptokurtic, which means that the distribution has heavier tails. A positively skewed distribution indicates that the right tail is longer than the left one. 
lower kurtosis value for PAP 13 . In case of $\mathrm{C}_{2}^{*}$, the maximum intensity value is higher in $\mathrm{CH}^{*}$ and $\mathrm{OH}^{*}$ is concentrated in a particular pixels area. Therefore, the shape of the curve is rather leptokurtic. The skewness is reduced for higher PAP values, as seen in Fig. 7. This trend is in accordance with kurtosis results. It implies that the intensity distribution is displaced to the right due to higher levels of intensity in the pixels that correspond to the secondary cone. Regarding radicals, $C_{2}^{*}$ has a higher value, because although the average level of intensity in the $C_{2}^{*}$ is lower, the maximum is higher. Therefore, the distribution has a larger right tail than in the case of $\mathrm{OH}^{*}$ and $\mathrm{CH}^{*}$.

\section{Spectrometry results}

Flame emission spectrometry results are given in Fig. 8 (a-f), where emission intensity appears in arbitrary units (a.u.). As aforementioned in section Experimental and methods, each spectrum represents the averaged signal of 100 raw samples

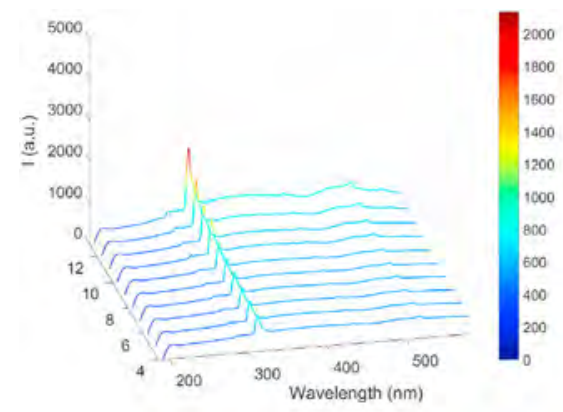

(a) $11 \mathrm{~cm}-\mathrm{G} 222$ gas

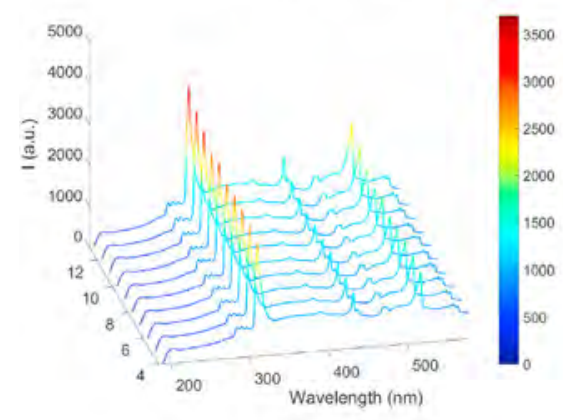

(c) $9 \mathrm{~cm}-\mathrm{G} 222$ gas

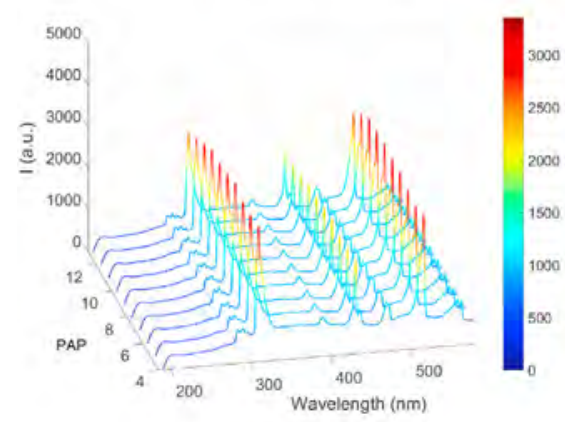

(e) $7 \mathrm{~cm}-\mathrm{G} 222$ gas registered at $100 \mathrm{~ms}$-integration time for each PAP condition and fuel tested. The maximum colour bar value in Fig. 8 (a-f) has been set to the maximum intensity of the spectra, in order to visualise more clearly the trends. The optic fibre vertical position tested was $7 \mathrm{~cm}, 9 \mathrm{~cm}$ and $11 \mathrm{~cm}$ above the burner table.

As expected, the intensity peaks of $\mathrm{OH}^{*}, \mathrm{CH}^{*}$ and $\mathrm{C}_{2}^{*}$ species, located at 310, 430 and $515 \mathrm{~nm}$, respectively can be clearly detected in the graphs, as well as the $\mathrm{CO}_{2}^{*}$ continuous background (340-650 $\mathrm{nm}$ ). The highest emission contribution is found at $7 \mathrm{~cm}$, which is related to the line-of-sight integrated flame radiation coming mainly from the fuelrich premixed reaction zones near the burner exit ports. The overall emission intensity decreases for the $\mathrm{H}_{2}-\mathrm{CH}_{4}$ blend (G222, shown in Fig. 8c and e). This effect has been also identified at fully premixed conditions [55]. Also, the $\mathrm{OH}^{*}$ intensity peak is higher for all spectra, except for G222$7 \mathrm{~cm}$ (Fig. 8e), where $\mathrm{OH}^{*}$ and $\mathrm{C}_{2}^{*}$ peaks are of the same order. For both fuels, at $9 \mathrm{~cm}$, the peak heights of $\mathrm{OH}^{*}, \mathrm{CH}^{*}$

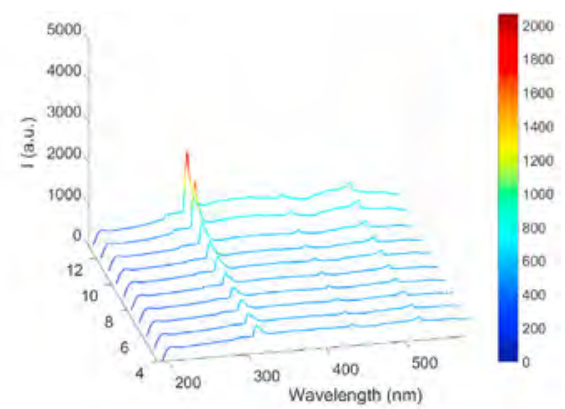

(b) $11 \mathrm{~cm}-\mathrm{G} 20$ gas

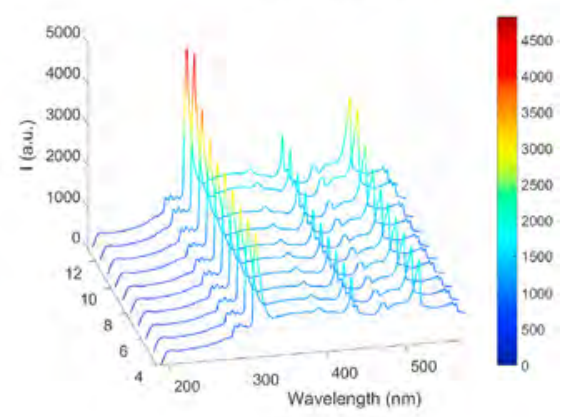

(d) $9 \mathrm{~cm}-\mathrm{G} 20$ gas

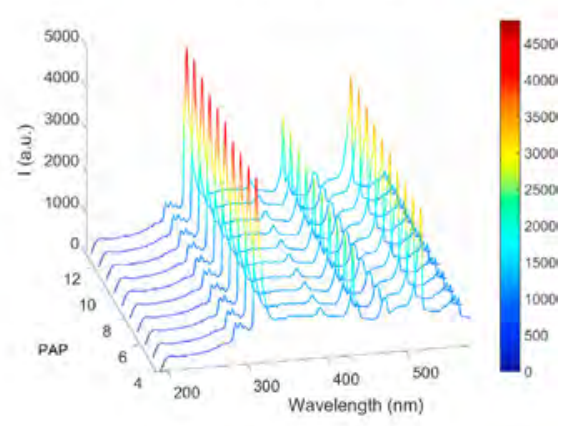

(f) $7 \mathrm{~cm}-\mathrm{G} 20$ gas

Fig. 8 - Measured spectra at various optic fibre tip heights above the burner support: (a-b) $11 \mathrm{~cm},(\mathrm{c}-\mathrm{d}) 9 \mathrm{~cm},(\mathrm{e}-\mathrm{f}) 7 \mathrm{~cm}$. 


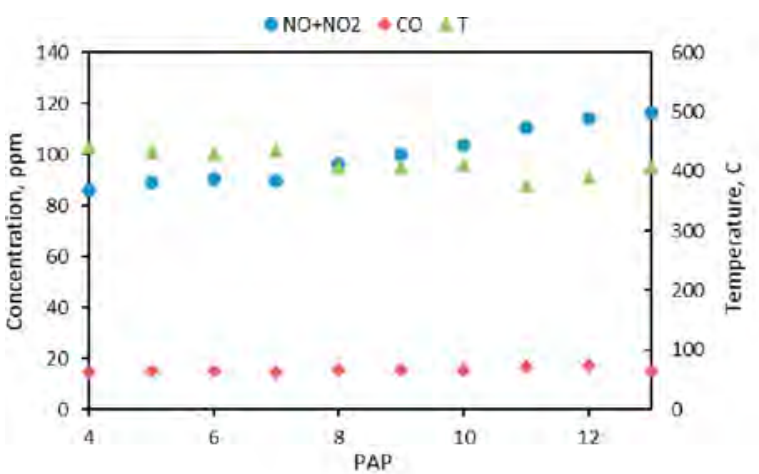

(a) G222

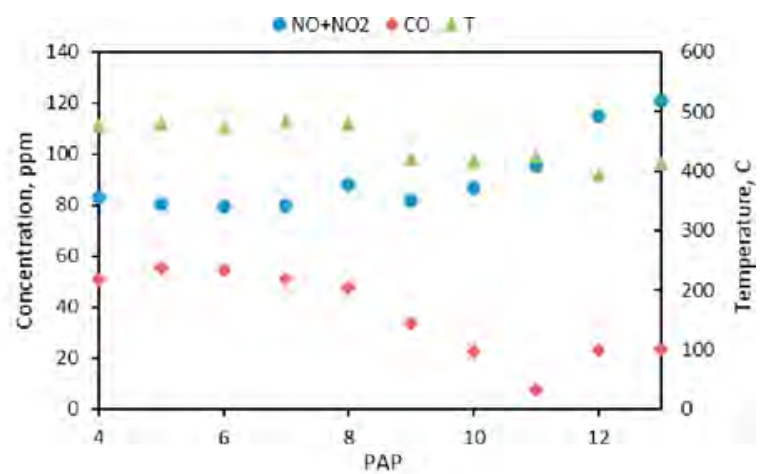

(b) G20

Fig. $9-\mathrm{NO}_{x}$, CO concentration in flue gases (at @ 0\% 02 dry) and temperature measured during the tests.

and $C_{2}^{*}$ species increase while reducing the primary air, which is in accordance with results from filtered EMCCD images shown in Fig. 6. The background generated by $\mathrm{CO}_{2}^{*}$, as well as the widened secondary outer cone and inner flames, due to the reduction of the primary air, contribute also to the increment. Nevertheless, the tendency is not maintained at $7 \mathrm{~cm}$ for the G222 gas (Fig. 8e), where the height of the peaks slightly decrease and the background does not seem to be influenced by the primary air reduction. In addition, the radiation emitted by $\mathrm{CH}^{*}$ and $\mathrm{C}_{2}^{*}$ species is higher for $7 \mathrm{~cm}$ as compared to $9 \mathrm{~cm}$ when PAP is increased, which is in accordance with the fact that the rich fuel-air premixed inner reaction zone is mainly related with the generation of $\mathrm{CH}^{*}$ and $\mathrm{C}_{2}^{*}$ species. In the case of $\mathrm{G} 20$, the tendency is that by increasing PAP, which leads to fuelricher conditions, the intensity of all radical peaks increased, especially in positions 12 and 13. At $7 \mathrm{~cm}$ height from the burner table, that is, when the spectrometer points to the flame roots, $\mathrm{OH}^{*}, \mathrm{CH}^{*}$ and $\mathrm{C}_{2}^{*}$ radicals tend to increase slightly with PAP. Results obtained differs from previous works with premixed flames, where the peak intensity decreases while lowering the air-to-fuel equivalence ratio (ER increases) $[21,56,57]$. The most probable explanation is that in the present study, the radiation detected by the optical fibre is generated in partially premixed conditions, where aside from the fuel rich premixed flames, an outer secondary non-premixed reaction zone is generated and contributes in a greater extent to the registered radiation. In general, the G222 spectra have lower intensity distribution than G20, probably caused by the slightly lower thermal input of G222. When burning G222, the trends of the emitted radiation from the excited species are similar to $\mathrm{G} 20$ at $9 \mathrm{~cm}$ height. However, at the height of $7 \mathrm{~cm}$, they tend to decrease slightly as the setting position increases, contrary to the case of G20. This may be caused by the faster hydrogen combustion kinetics [26]. At $11 \mathrm{~cm}$ height, only the hydroxyl radical species presents significant intensity in the flame emitted spectra, which increases with PAP for both fuels. This effect is in accordance with EMCCD filtered images (Fig. 4b, f, $j$ and $n$ ).

Finally, results from filtered EMCCD images exhibit similar trends to the $\mathrm{OH}^{*}$ peak evolution observed in the spectra, specially for the $9 \mathrm{~cm}$ data. The $\mathrm{OH}^{*}$ peak increases monotonically with PAP, which highlights the relevance of this species in the outer secondary cone reaction zone.

\section{Emissions results}

As outlined in the experimental section (Experimental and methods), $\mathrm{NO}_{x}$ ( $\mathrm{NO}+\mathrm{NO}_{2}$ ), $\mathrm{CO}$ and temperature were simultaneously measured at the exhaust hood while acquiring flame images during the tests. Average results are

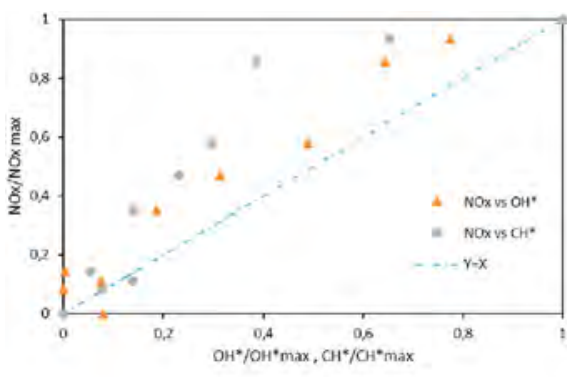

(a) G222

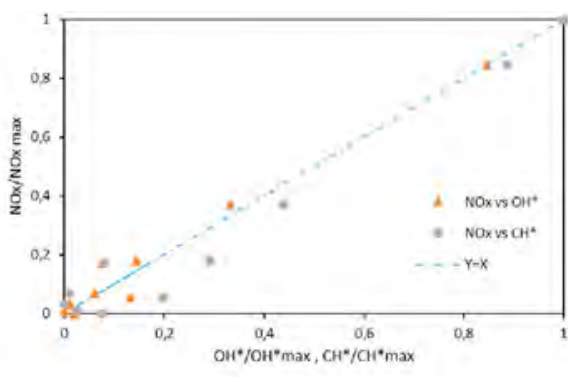

(b) G20

Fig. 10 - Normalised $\mathrm{NO}_{x}$ emissions vs $\mathrm{CH}^{*}$ and $\mathrm{OH}^{*}$ normalised intensity: a) G222, b) G20. 

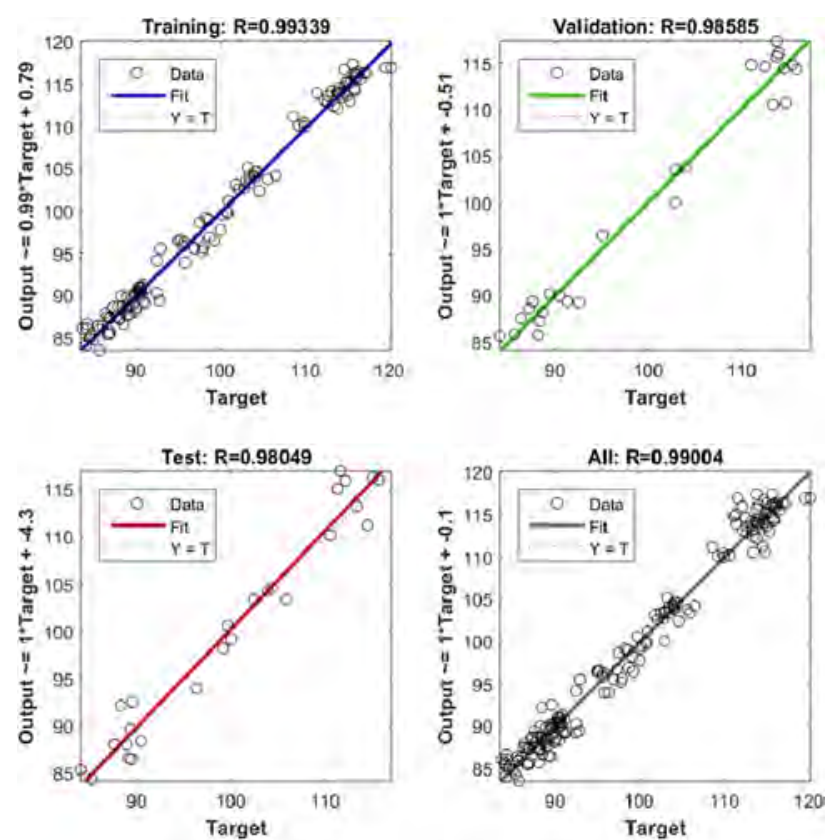

(a) $\mathrm{G} 222$
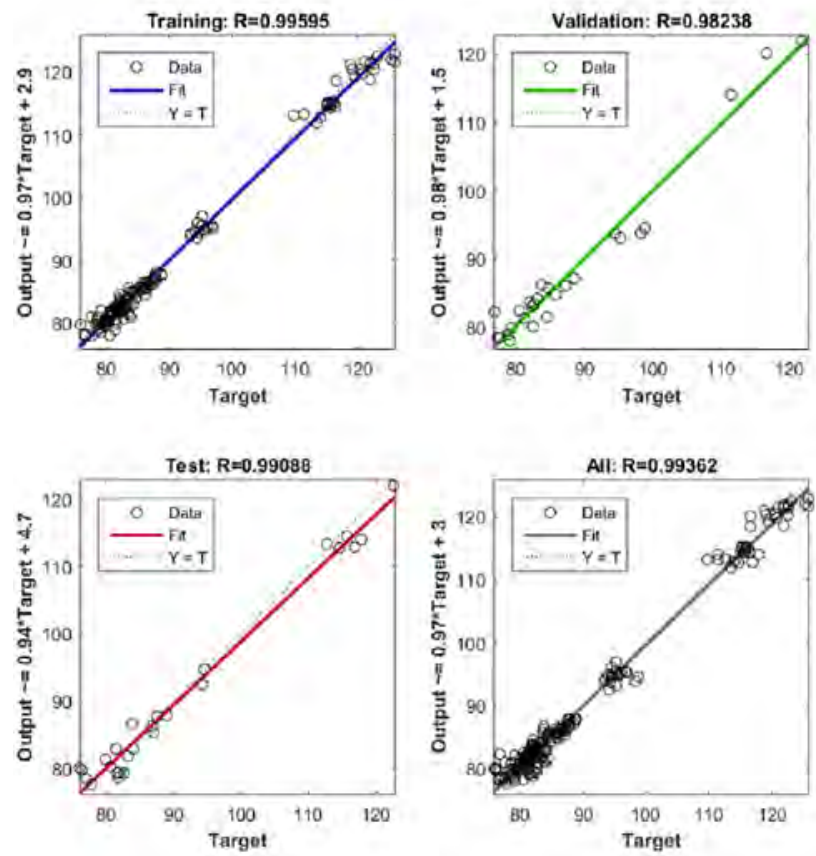

(b) G20

Fig. 11 - NOx-ANN prediction model results for (a) G222 and (b) G20 (70\% of data).

shown in Fig. 9 for both fuels. Results shows values of similar order, although a lower $\mathrm{CO}$ concentration has been measured for G222 tests than G20, which is expected, due to the faster combustion kinetics of hydrogen. This effect was also found by Burbano et al. [39]. Despite it is claimed that $\mathrm{H}_{2}$ could increase $\mathrm{NO}_{x}$ emissions by its higher adiabatic flame temperature, the range of $\mathrm{NO}_{x}$ is very similar. The increasing $\mathrm{NO}_{x}$ trend when decreasing the primary air agrees with other published results for this kind of burners [44].

Fig. 10 shows the variation of the $\mathrm{NO}_{x}$ emissions, normalised by its maximum, with the $\mathrm{CH}^{*}$ and $\mathrm{OH}^{*}$ intensity, also normalised by its maximum, obtained from Fig. $6 a$ and $b$. The normalization has been applied due to the difference in transmittance and bandwidth of the filters. Results are in accordance with other works [37,58-60]. A monotonically 

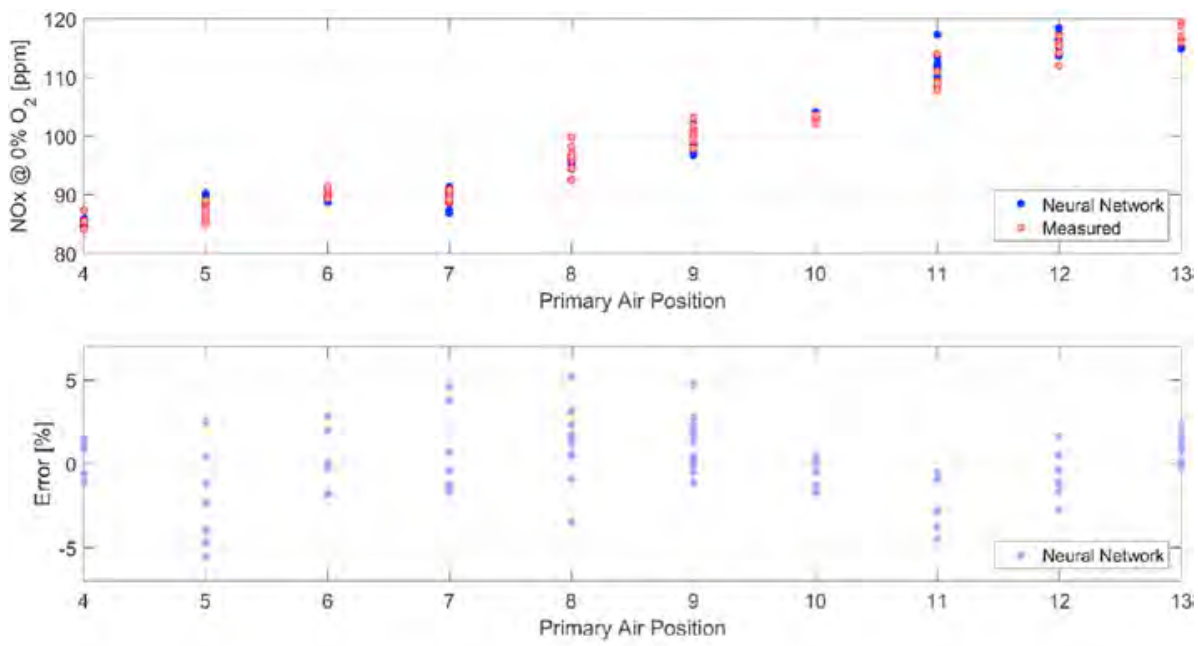

(a) G222
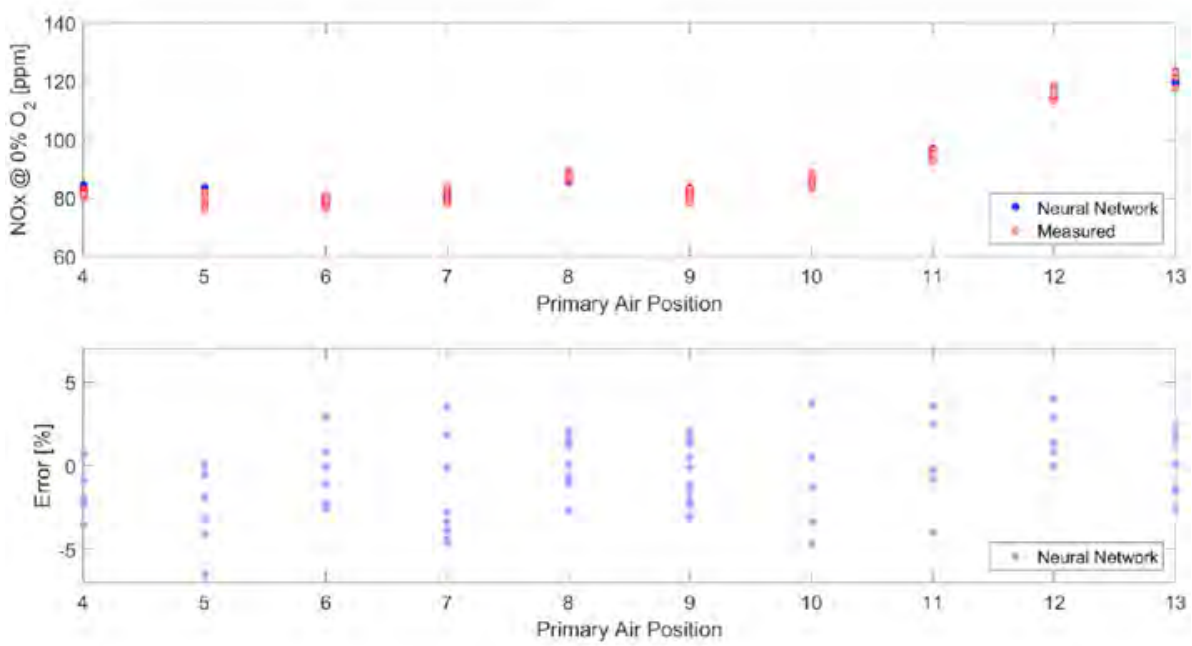

(b) G20

Fig. 12 - Measured and predicted $\mathrm{NO}_{x}$ concentration and error for (a) G222 and (b) G20 (remaining $30 \%$ of data).

direct relationship between $\mathrm{NO}_{x}$ and the normalised intensity of the excited species $\mathrm{CH}$ and $\mathrm{OH}$ can be clearly appreciated in the figure, although the trend is non-linear and shows more dispersion in data for G222 than for G20.

\section{Results of the ANN}

Two neural networks have been trained with available experimental data of G222 and G20 fuel gases. Figs. 11a and 12 a show G222 results. Collected data (70\% of total) was randomly split into training (70\%), validation (15\%) and test (15\%). Fig. 11a shows the relationship between the outputs of the network and targets. The correlation coefficients $\mathrm{R}$ were $0.99339,0.98585$ and 0.98049 in the training, validation and test data, respectively. Moreover, the global correlation coefficient obtained was 0.99004 , which indicates a good performance of the model.
Once the network was trained, the model was used to estimate $\mathrm{NO}_{x}$ emissions in the remaining $30 \%$ of collected data. Results are presented in Fig. 12a for G222. The upper subplot shows the $\mathrm{NO}_{x}$ concentration @ 0\% O2 in ppm at each PAP for G222 gas. Red and blue points indicate measured and predicted values, respectively. The bottom subplot shows the error in percentage between measured and ANN values. The error is slightly larger for low primary air positions but is below $5.7 \%$ in all tested points. The maximum error corresponds to PAP 5.

Similarly, the results of the $\mathrm{NO}_{x}$-ANN predictive model for G20 are presented in Figs. $11 \mathrm{~b}$ and $12 \mathrm{~b}$. The same procedure was used. Fig. 11b shows the relationship between the outputs of the network and targets. The correlation coefficients $\mathrm{R}$ obtained were $0.99595,0.98238$ and 0.99088 in the training, validation and test data, respectively. The global correlation coefficient $\mathrm{R}$ was 0.99362 , which indicates also a rather good 
performance. Once the network was trained, the model was used to estimate the $\mathrm{NO}_{x}$ emissions in the test data (30\%). Results are presented in Fig. 12b. The error is slightly larger for low primary air positions but is below $6.5 \%$ in all tested points. The maximum error corresponds also to PAP 5. Furthermore, a sensitivity analysis and the detailed description of the ANN have been included in Appendix $C$ in order to evaluate the influence of input variables and image sequences.

\section{Conclusions}

One of the main goals of this study was to illustrate the feasibility of machine learning algorithms and imaging techniques to predict NOx emissions in partially-premixed burners. A UV-VIS EMCCD camera, equipped with narrow-band optical filters for detecting $\mathrm{OH}^{*}, \mathrm{CH}^{*}$ and $\mathrm{C}_{2}^{*}$ species, a portable spectrometer and a gas analyser were used for burner characterization. Images were processed and statistical image flame features were extracted and analysed. The effects of hydrogen addition and primary air reduction on burner performance and emissions have been evaluated. Finally, in order to test the flame imaging capabilities, a $\mathrm{NO}_{x}$ emissions predictive model based on flame imaging features has been developed and tested. Main results and conclusions are summarised as follows:

- The double-cone flame structure, typical of partiallypremixed flames is developed, showing multiple premixed flames close to the burner exit, and an outer nonpremixed zone. Although the reduction of the primary air generates flames with lower values of maximum intensity, the image area with significant intensity increases, in particular for $\mathrm{OH}^{*}$ and $\mathrm{CH}^{*}$ images. The inner reaction zone is thinner and shorter for the $\mathrm{H}_{2}-\mathrm{CH}_{4}$ blend, as compared to $\mathrm{CH}_{4}$, caused by the slightly higher laminar burning velocity of the blend and higher hydrogen reactivity, which results in shorter flames.

- For both gases and all test conditions an upward trend of the mean intensity value when the primary air mass flow is reduced can be clearly distinguished for all optical filters. The overall intensity increases for higher PAP, which can be related to the contribution of a larger reaction zone. Flame spectra analysis agrees with radical imaging, showing that the highest intensity distribution of the flame emitted radiation is found at $7 \mathrm{~cm}$, coming mainly from the fuel-rich premixed reaction zones near the burner ports.

- Emission results show $\mathrm{NO}_{x}$ values of similar order for both fuels. An increasing $\mathrm{NO}_{x}$ trend is also detected when decreasing the primary air. However, a lower CO concentration has been measured for G222 tests due to the faster combustion kinetics of hydrogen. A monotonically direct relationship between $\mathrm{NO}_{x}$ and the normalised intensity of $\mathrm{CH}^{*}$ and $\mathrm{OH}^{*}$ can be clearly appreciated, in agreement with other related research works.

- It has been demonstrated that a $\mathrm{NO}_{x}$ predictive model can be built, based on flame imaging features and using machine learning techniques. LDA outperformed all tested algorithms, with a $98 \%$ of accuracy in the estimation of the outputs. ANN correlation coefficient R was 0.99004 and 0.99360 , for G222 and G20, respectively. The ANN error was slightly larger for low primary air positions in both models, although their maximum values were $5.7 \%$ and $6.5 \%$ for separate data testing, for G222 and G20, respectively. Finally, results from the sensitivity study shows that the influence of the number of inputs in the model is lower than the influence of the image sequences.

\section{Declaration of competing interest}

The authors declare that they have no known competing financial interests or personal relationships that could have appeared to influence the work reported in this paper.

\section{Acknowledgments}

This work has received funding from the European Union's Horizon 2020 Research and Innovation Programme under the Grant Agreement No. 636834 (DISIRE Project) and Spanish MICINN (ENE2013-48003R). CH is supported by ENEA-Italian Ministry for Economic Development under the programme "Ricerca di Sistema elettrico nazionale" (RdS PTR19-21 - 1.6). The authors wish to thank to Oscar Puyó and Simón Salas for their support and help during the experimental tests and also to Dr. Cristina Gonzalo-Tirado for her fruitful discussions.

\section{Appendix}

\section{A. Experimental facility}

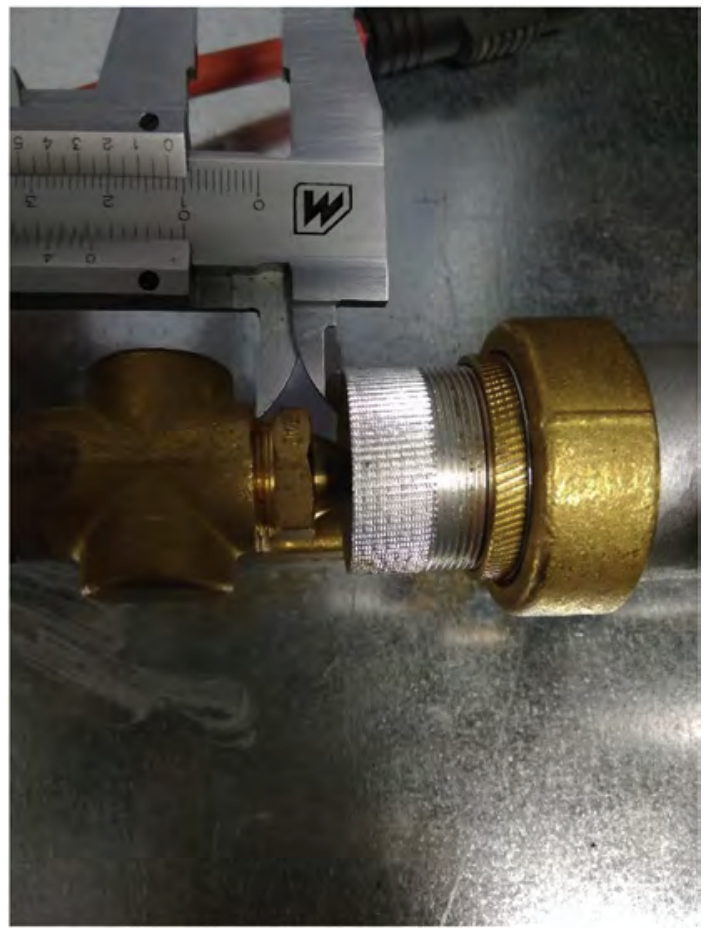

Figure A.13 - Detail of the primary air shutter. 


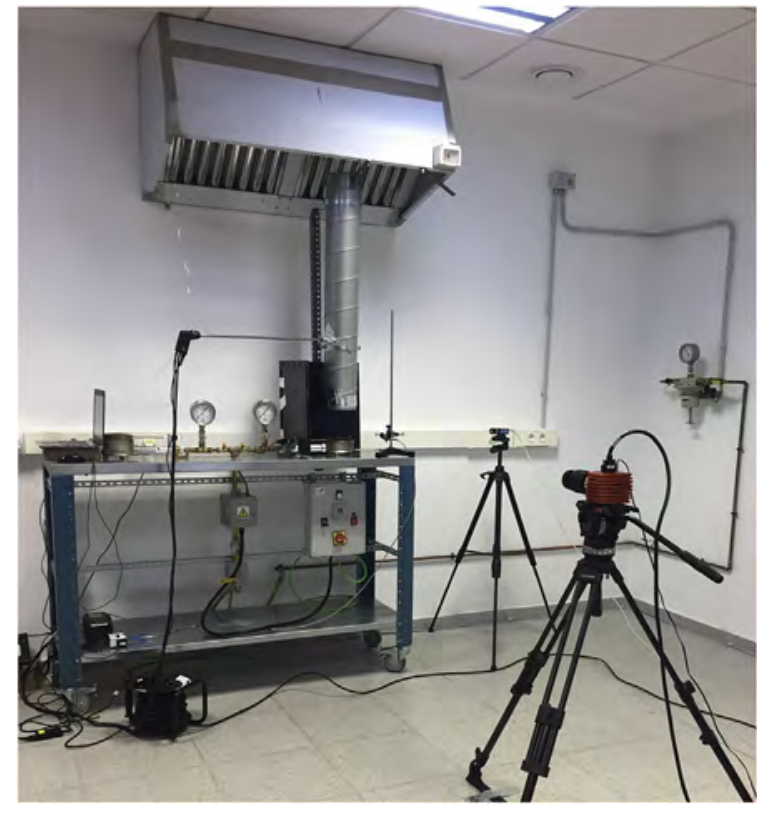

Figure A.14 - Experimental set-up.

\section{B. Modelling primary air entrainment flow}

The primary air intake is not usually measured in selfaspirated gas burners. By changing the injector diameter size and/or the fuel gas pressure, the fuel flow rate can be regulated, and the primary air enters from the ambient air by the well-known Venturi effect. As a common practice, these burners often work at fuel rich conditions (lower primary air than stoichiometric) for flame stability and safety reasons $[44,61]$. If the distance between the gas injector and the venturi entrance is fixed at a certain position and the other parameters do not substantially change, the primary air-to-fuel ratio remains constant. In the present test-rig the primary air has been reduced for a given injector discharge gas pressure. The air shutter has been closed at certain fixed positions (see figure A.13 and Table 2), which increases the friction loss in the venturi mixing tube, lowering the quantity of air entrained from the ambient to the burner head and hence, decreasing the primary air to fuel ratio. In other works the primary air flow rate was indirectly measured by inserting the flue gas analyser probe directly in the burner head [62]. However, in the present case, this technique was discarded for safety reasons. Alternatively, it was estimated using basic air entrainment equations combined with experiments carried out with an inert gas $\left(\mathrm{N}_{2}\right)$ in order to provide an order-ofmagnitude value. The modelling approach is based on the entrained flow equations through a venturi tube, derived by applying simple momentum and energy balances to the airfuel mixing process in the venturi and to the fuel discharge from the injector and mixture from the burner ports, according to the work of Jones [44]. However, the effect of modifying the inlet geometry of the venturi is not usually reported in literature. Therefore, in order to tackle with this, a more general approach has been used. The relation is derived by applying: (1) a momentum balance between the fuel injector outlet (subscript i) and the throat (subscript t) neglecting stream contraction; (2) an energy balance between the throat and the diffuser outlet (burner head or port, subscript $p$ ), and two energy balances for discharge from the injector and from the burner ports to the ambient, respectively ([44]). By combining the equations, and defining $R$ as the ratio of the entrained volumetric flow rate of primary air relative to the jet gas $\left(R=\frac{\dot{V}_{a}}{\dot{V}_{g}}\right), \sigma$ as the relative gas-air density $\left(\sigma=\frac{\rho_{g}}{\rho_{a}}\right), \dot{V}_{m}$ as the volumetric flow rate of the mixture $\left(\dot{\mathrm{V}}_{m}=\dot{\mathrm{V}}_{g}(1+R)\right)$ and $\rho_{m}$ as the mixture density $\left(\rho_{m}=\frac{\rho_{g}(\sigma+R)}{\sigma(1+R)}\right)$ it yields

$$
\frac{(\sigma+R)(1+R)}{\sigma} \cdot \frac{\left(\frac{A_{i}}{A_{p}}\right)^{2}}{C_{D_{p}}^{2}}=\frac{2\left(\frac{A_{i}}{A_{t}}\right)^{2}}{1+\left(\frac{A_{p}}{A_{t}}\right)^{2} C_{D_{p}}^{2}\left(1+C_{L}\right)}
$$

In eq. (B.1), $C_{D_{p}}$ is the discharge coefficient from the flame burner ports, which depends basically on the geometry and Reynolds number. As the mixture exits through multiple flame orifices, the velocity decreases and the flow becomes laminar, so there is a strong dependence on Re number. $C_{D_{p}}$ values are obtained from Refs. [44], based on previous studies [63]. Values lay within the range of $0.58-0.63$ for a burner port orifice Reynolds number within 400-700, in accordance with typical burner operation [44]. Note that equation B.1 is implicit in $R$, due to the fact that the discharge coefficient through the burner ports $C_{D_{p}}$ largely depends on the burner ports Reynolds number $R e_{p}$ which in turn depends also on $R$ via $\dot{V}_{a}$. Finally, $C_{L}$ is the friction loss coefficient for the whole mixing tube, relative to the throat section. As the regime is turbulent at the mixing zone, $C_{L}$ is mainly a function of the shape and roughness of the conduct. However, if the movable piece of the venturi is adjusted by increasing the thread pitches (figure A.13), the shape of the mixing tube is modified, increasing the flow resistance and $C_{L}$, resulting in lower entrained primary air flow rates.

Summarising, for a given $R$, the friction loss coefficient of the venturi $C_{L}$ can be determined from equation B.1, and vice versa. Therefore, in the present research, the primary air to fuel ratio $R$ has been experimentally estimated by eq. B.1 using additional testing. Instead of fuel, an inert gas (pure nitrogen) has been used as the jet fluid for convenience and safety reasons. The methodology adopted here is partly based on the work of Namkhat and Jugjai ([62]), who measured the oxygen concentration at the burner ports with an oxygen sensor. Using the oxygen sensor available in the flue gas analyser the oxygen concentration $\left(\% \mathrm{O}_{2}\right)$ was measured at the exit of the burner ports and $R$ was determined as function of the primary air position (PAP) from $\mathrm{N}_{2}$-tests using Eqn B.2:

$$
\mathrm{R}_{\mathrm{N}_{2}}=\frac{\% \mathrm{O}_{2}}{20.96-\% \mathrm{O}_{2}}
$$

Experiments were carried out at ambient conditions. Ambient room temperature was kept at $300 \mathrm{~K}$ during all tests. The burner was externally shielded to prevent secondary air entrainment, while maintaining constant ambient pressure at the exit. As the oxygen sensor has an accuracy of $\pm 0.2 \% a b$ solute, using a $95 \%$ confidence interval, the maximum and minimum uncertainties in $R_{\mathrm{N}_{2}}$ were found to be \pm 8.5 and $6.3 \%$ relative. All thermodynamic and transport properties were 
obtained and necessary equations were solved using the software Engineering Equation Solver.

Once $R_{N_{2}}$ values were known, the experimental friction loss coefficient $C_{L}$ was obtained from $\mathrm{N}_{2}$-tests by substitution in eq. B.1, and the primary air to fuel equivalence ratio (relative to the stoichiometric value) for both fuels (G20 and G222) was estimated by solving eq. B.1 for each fuel gas for determining R. Results are shown in figure B.15 and Table 3. Comparison show similar trends for both fuels. However, although $R_{G 20}$ values are higher than $R_{G 222}$ ones, due to the higher relative density of G20, the primary-air to fuel equivalence ratio for G20 gives lower values, due to the higher stoichiometric air requirements for pure methane, as compared to the $\% 77 \mathrm{CH}_{4}-\% 23 \mathrm{H}_{2}$ blend. This fact agrees with recent research $[40,41]$ with $\mathrm{H}_{2}-\mathrm{CH}_{4}$ gaseous mixtures in cooktop burners.

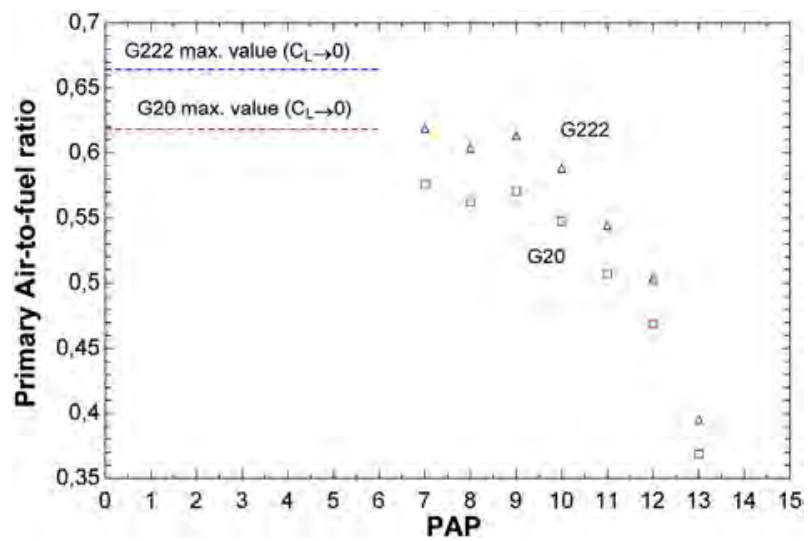

Figure B.15 - Estimated primary air-fuel equivalence ratio (relative to the stoichiometric value) as function of PAP (see Table 2 for details), showing the theoretical limit value $\left(\mathrm{C}_{\mathrm{L}}=0\right)$.

Nevertheless, results obtained can be used for reference only, because they are obtained at ambient conditions. At working conditions, since the burner head is slightly heated by radiation and conduction from the flame root, the aspirated primary air is expected to be up to $10 \%$ lower [62].

\section{LDA/NN NOx modelling}

\section{C.1. Classification algorithm}

Classification is a type of machine learning algorithm, included in the Supervised Learning Algorithms group [58,64]. This type of algorithm is used when the response is a choice between classes (gas and primary air position). It learns to distinguish new observations from examples of labelled data.

C.1.1. Description of the classification algorithm. A scheme of the classification block diagram is shown in figure C.16. The classification algorithm enables to classify the data taking into account the primary air position and the type of gas (G20 or G222). A total amount of 342000 experimental flame images were used to obtain the input parameters of the classification algorithm. It corresponds to 25 sequences of 228 photos in each of the 10 Primary Air positions (4-13), three filters $\left(\mathrm{OH}^{*}\right.$, $\mathrm{CH}^{*}$ and $\mathrm{C}_{2}^{*}$ ) and 2 types of gases (G222 and G20). Images were randomly split into training data $(70 \%$ of the total amount of data: 350 sequences) and test data (30\% of the total amount of data: 150 sequences).

According to previous studies with CCD cameras [9], eighteen statistical and geometrical features, which are representative of experimental flame images were computed from experimental flame images. A categorical variable defined as [Primary Air Position]-[Gas] was selected as the output of the classification algorithm. The classification learner tool in MATLAB ${ }^{\circledR}$ was used to perform the classification algorithm. Using this application, different classifiers can be selected, including decision trees, discriminant analysis, support vector machines, logistic regression, nearest neighbours and ensemble classification. A supervised classification algorithm was built by supplying a known set of input data (flame radical characteristics) and known responses to the data (fuel gas and primary air position class). The input data was used to train the model and thus, to predict the response of new data. Among all tested, the Linear Discriminant Analysis achieved the best classification results. The diagonal covariance was used as the regularization method [65]. Results show a $98 \%$ of accuracy in the estimation of the outputs.

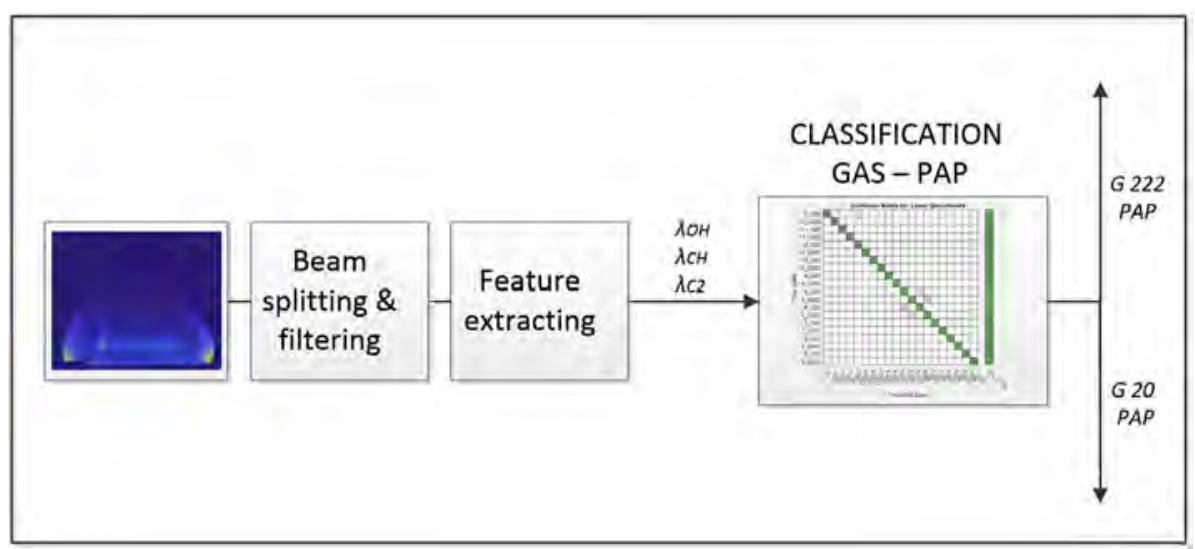

Figure C.16 - Step 1: Prediction of type of gas and primary air position through flame radical imaging. 
In this algorithm, each class $(\mathrm{Y})$ generates data $(\mathrm{X})$ using a multivariate normal distribution. The model assumes that $\mathrm{X}$ has a Gaussian mixture distribution. For linear discriminant analysis, the model has the same covariance matrix for each class. The function classifies the data in order to minimise the expected classification cost, according to eq. C.1:

$\widehat{y}=\underset{y=1, \ldots, K}{\arg \min } \sum_{k=1}^{K} \widehat{P}(k \mid x) C(y \mid k)$

where $\hat{y}$ is the predicted classification, $K$ is the number of classes (20, in this case), $\widehat{P}(k \mid x)$ is the posterior probability of class $\mathrm{k}$ for the observation $\mathrm{x}, \mathrm{C}(\mathrm{k} \mid \mathrm{x})$ is the cost of classifying an observation as $y$ when its true class is $k$. The arg min function returns the value of $y$ which minimises the function within the sum.

C.1.2. Results of the classification algorithm. Figure C.17 shows the confusion matrix for the Linear Discriminant Analysis applied to this particular case. Rows and columns show the true classes and the predicted classes, respectively. It can be seen that the algorithm has misclassified three of the 350 training data (70\% of the total data). Some points of the Primary Air Position (Position 5 and 6) are misclassified in both gases (G222 and G20), due to the small differences in input variables.
Figure C.18 shows an example of the classification between groups, where the $\mathrm{CH}^{*}$ intensity is plotted versus $\mathrm{OH}^{*}$ for all groups using a scatter plot. Circles corresponds to points that have been positively classified and crosses corresponds to misclassified points. Each color represents a group of the pair PAP-Gas. In this case, only some points has been misclassified during the application of the LDA algorithm.

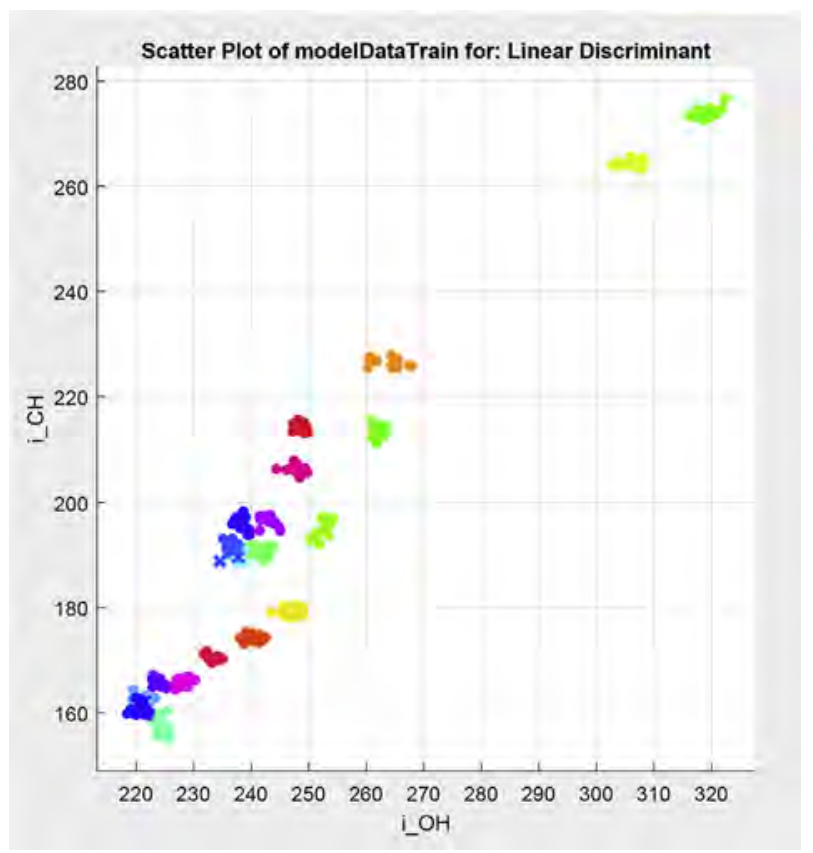

Figure C.18 $-\mathrm{I}_{\mathrm{CH}} *$ vs $\mathrm{I}_{\mathrm{OH}} *$ in each of the groups.

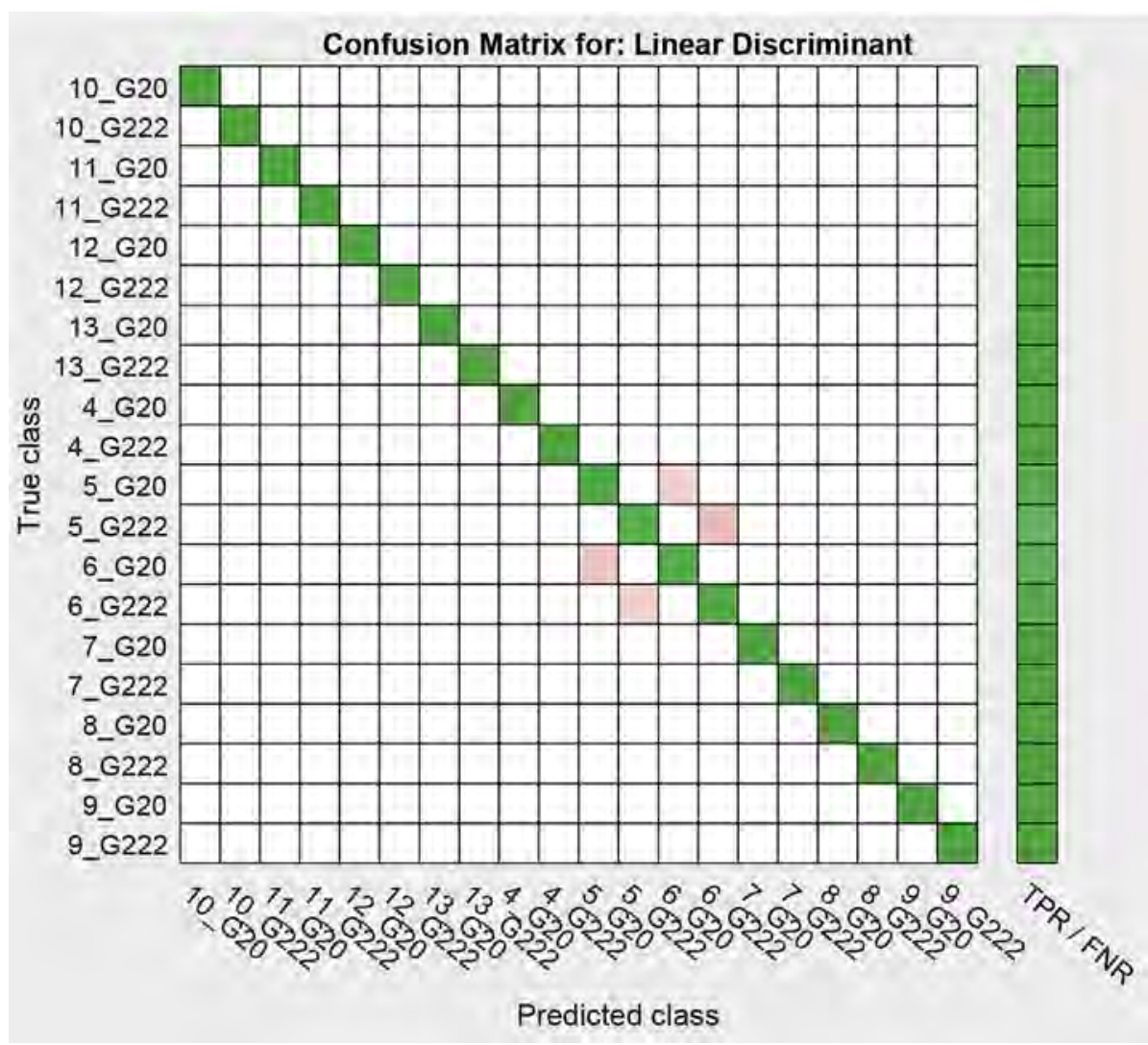

Figure C.17 - Confusion matrix PAP-Gas. 
Once the model was trained, the following step consists of testing the model in the remainder 150 test data, which corresponds to $30 \%$ of the global experimental data. A random order has been applied to the model in order to avoid overfitting and underfitting. Figure C.19 depicts the results of the classification model, showing the number of points (histogram) that corresponds to a particular class (PAP-GAS) in the predicted and in the measured case. The comparison between both subplots could give a rough estimate of the precision of the classification model. Figure C.19 subplot A shows the histogram obtained from data predicted by the model using the inputs from flame imaging characteristics. Subplot B shows the histogram obtained directly from measured data (obtained from the 30\% of the global experimental data). From the chart, similar trends are identified in both predicted and measured data in all the Primary Air Positions and in both gases. considering Primary Air Position (PAP), fuel gas (G20 or G222) and statistical and geometrical flame imaging features as inputs. In this case, PAP and fuel gas type were obtained as outputs from the results of the previous classification algorithm. Therefore, two ANN were modelled, one for each gas. A scheme of the block diagram in the ANN is shown in Fig. 3. A total amount of 171,000 experimental flame images were used to obtain inputs for each $\mathrm{ANN} \mathrm{NO}_{x}$ emissions were averaged during each $30 \mathrm{~s}$ period. A total amount of 250 average data were used in the model for each gas. Captured images were split into a set of training (70\% of total), validation (15\%) and test data (15\%). Eighteen representative features of the flame imaging radicals were used as inputs to the ANN. These features correspond to the same parameters as the ones used in the classification algorithm. However, in this case a preprocessing method was used to obtain the ratios of the inputs $\left(\mathrm{OH}^{*} / \mathrm{CH}^{*}, \mathrm{C}_{2}^{*} / \mathrm{OH}^{*}, \mathrm{C}_{2}^{*} / \mathrm{OH}^{*}\right)$ to feed the ANN, according to Ref. [58]. This allows scaling all features on the same scale,
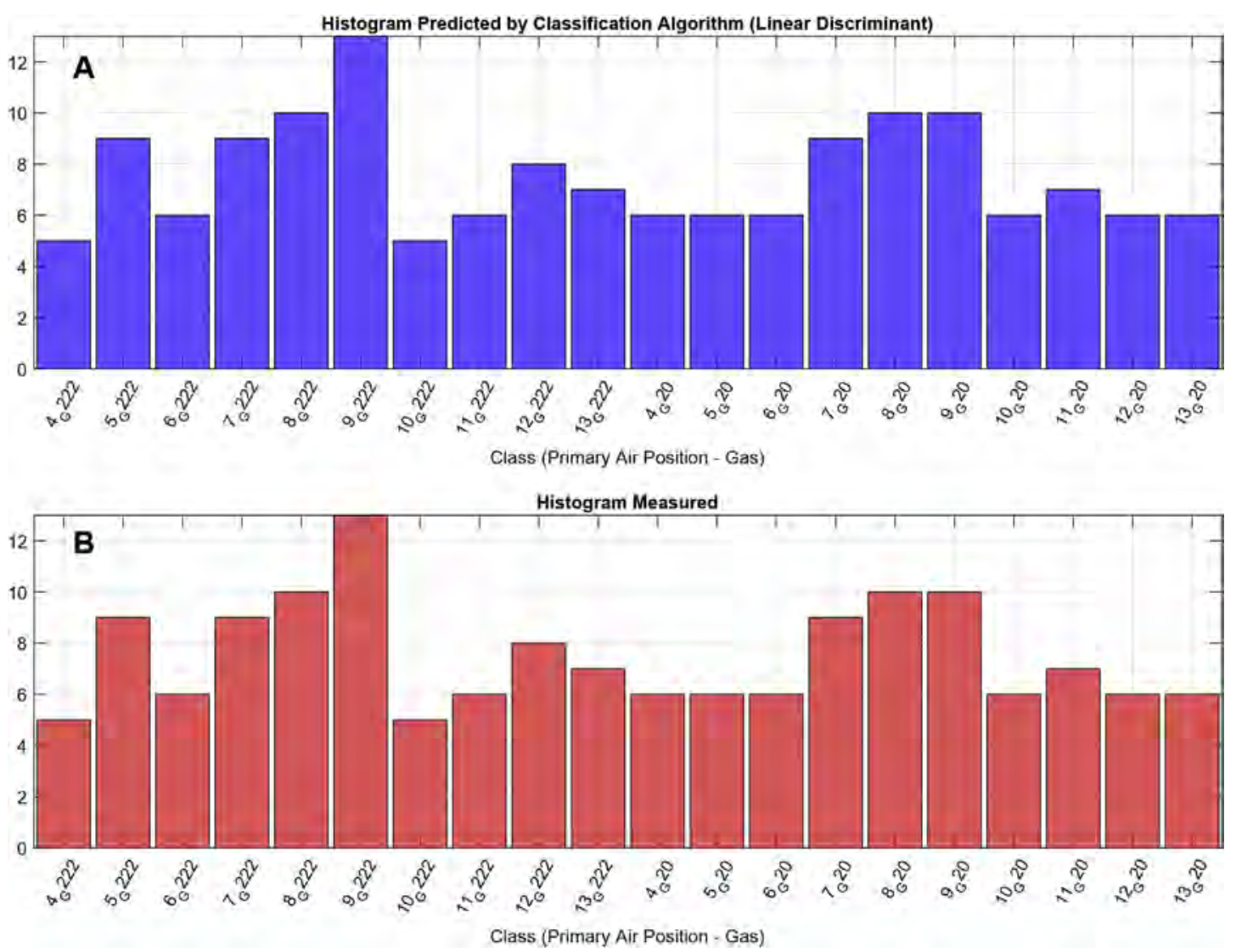

Figure C.19 - Results of the classification algorithm: Histogram A) predicted B) measured.

\section{C.2. Artificial Neural Network}

An Artificial Neural Network (ANN) is a type of supervised machine learning algorithm if the desired output is already known. Nowadays, ANNs have become common techniques for modelling non-linear systems with several inputs and outputs, such as $\mathrm{NO}_{x}[31,64]$. A Neural Network model was implemented in MATLAB ${ }^{\circledR}$ to predict $\mathrm{NO}_{x}$ emissions and therefore, achieving a better prediction using normalization.

In both ANNs for each type of gas, a standard two-layer feedforward network trained with Levenberg-Marquardt $([66,67])$ was used to predict $\mathrm{NO}_{x}$ emissions using the ratios of radical features, the type of gas and the Primary Air Position. The best results were achieved with a network composed 
of 18,10 and 1 neurons in the input, hidden and output layer, respectively. The updated version of Levenberg-Marquardt algorithm [66-68] was used to train the network. This algorithm is considered to be the fastest and most efficient method for training moderated-sized feed-forward neural networks which have up to a few hundred weights [69]. The Mean Squared Error (MSE), the averaged squared difference between estimated and actual values has been used as a measure of the ANN error. The algorithm gave convergence after 12 epochs. The activation function was the sigmoid symmetric transfer function. A mini-batch model was used because the size is greater than one but less than the total dataset size. It corresponds to the $70 \%$ of collected data. A value of 0.01 was used in the learning rate.

C.2.1. Sensitivity analysis. Sensitivity analyses are essential to understand the influence of the input variables in predictive models. Therefore, two sensitivity analyses were performed to investigate the effect of reducing the number of inputs and the number of images in the model, using the ANN of the G222 gas. General conclusions can be extrapolated to G20 gas. The first sensitivity study reduced the number of sequences of each input from 25 to 5 . The results are presented in figure C.20 which shows the error in percentage between the targets and outputs. As a consequence of this reduction, the model error increased from approximately 5\%-20\%. Therefore, the first remarkable point is that reducing the number of sequences below 20 might produce an underfitting problem, while increasing the number over 25 can produce an overfitting problem. The second sensitivity study was carried out reducing the number of NN inputs from 18 to 3 . The error in percentage between the targets and outputs is plotted in figure C.21. In this study the model error increased from approximately $5 \%-11 \%$. Therefore, the second remarkable point is that the influence of the number of inputs in the model output is weaker than the influence of the number of image sequences.

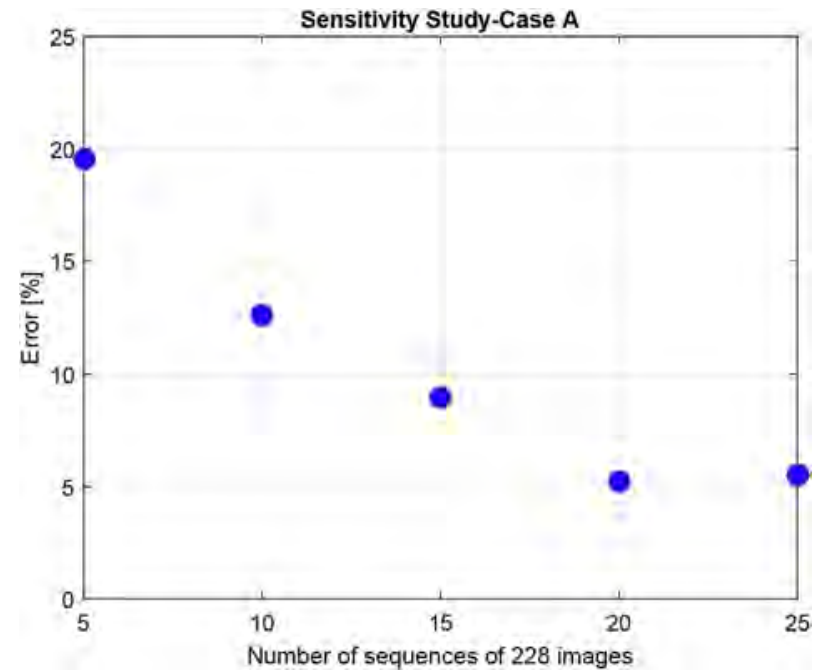

Figure C.20 - Sensitivity study case A: Effect of the image sequences.

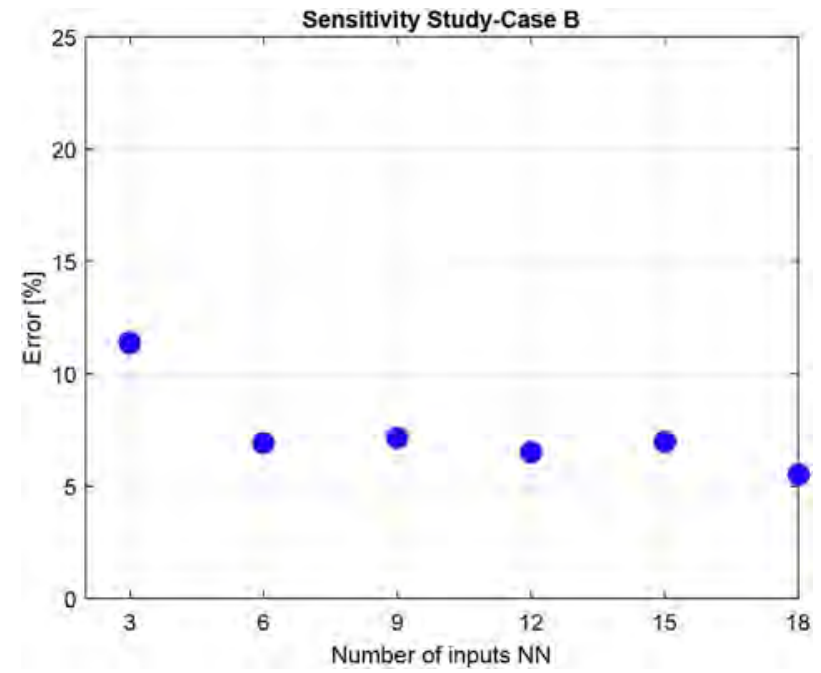

Figure C.21 - Sensitivity study case B: Effect of the number of ANN inputs.

\section{Nomenclature}

Abbreviations

AFR Air-Fuel Ratio

ANN Artificial Neural Network

CCD Charged Coupled Device

EMCCD Electron-Multiplied Charged Coupled Device

HHV High Heating Value, kW

LDA Linear Discriminant Analysis

MSE Mean Squared Error

$P A P \quad$ Primary Air Position

RGB Red Green Blue

TIFF Tagged Image File Format

UV - VIS Ultraviolet-Visible

Greek

$\rho$ density, $\mathrm{kg} / \mathrm{m}^{3}$

$\sigma \quad$ fuel-air relative density

Other symbols

$\dot{V} \quad$ Volumetric flow rate, $\mathrm{m}^{3} / \mathrm{s}$

A Area, $\mathrm{m}^{2}$

$C_{D_{i}} \quad$ injector orifice discharge coefficient

$C_{D_{p}} \quad$ burner port discharge coefficient

$C_{L} \quad$ friction loss coefficient of the mixing tube

G20 reference gas $\left(100 \% \mathrm{CH}_{4}\right)$

G222 reference gas $\left(23 \% \mathrm{H}_{2}, 77 \% \mathrm{CH}_{4}, \%\right.$ vol. $)$

$\mathrm{P} \quad$ Pressure, $\mathrm{Pa}$

$R \quad$ primary air to fuel gas volumetric flow rate ratio

Subscripts

a air

gas

i inlet

m mixture

o outlet, ambient

t throat 
Combust Flame 2017;181:110-22. https://doi.org/10.1016/ j.combustflame.2017.01.032.

[16] González-Espinosa A, Herce C, Gil A, Brunet F. Emission spectroscopy measurements in an industrial cracking furnace for combustion monitoring. Eur Combust Meet ECM 2017;2017(April):18-21.

[1] Sánchez AL, Williams FA. Recent advances in understanding of flammability characteristics of hydrogen. Prog Energy Combust Sci 2014;41(1):1-55. https://doi.org/10.1016/ j.pecs.2013.10.002.

[2] Taamallah S, Vogiatzaki K, Alzahrani FM, Mokheimer EM, Habib MA, Ghoniem AF. Fuel flexibility, stability and emissions in premixed hydrogen-rich gas turbine combustion: technology, fundamentals, and numerical simulations. Appl Energy 2015;154:1020-47. https://doi.org/ 10.1016/j.apenergy.2015.04.044.

[3] Davazdah Emami S, Kasmani RM, Hamid MD, Che Hassan CR, Mokhtar KM. Kinetic and dynamic analysis of hydrogen-enrichment mixtures in combustor systems - a review paper. Renew Sustain Energy Rev 2016;62:1072-82. https://doi.org/10.1016/j.rser.2016.05.029.

[4] Romero C, Li X, Keyvan S, Rossow R. Spectrometer-based combustion monitoring for flame stoichiometry and temperature control. Appl Therm Eng 2005;25(5-6):659-76. https://doi.org/10.1016/j.applthermaleng.2004.07.020.

[5] Arias L, Torres S, Sbarbaro D, Farias O. Photodiode-based sensor for flame sensing and combustion-process monitoring. Appl Optic 2008;47(29):5541-9. https://doi.org/ 10.1364/AO.47.005541.

[6] Guyot D, Guethe F, Schuermans B, Lacarelle A, Paschereit CO. $\mathrm{CH} * / \mathrm{OH}^{*}$ chemiluminescence response of an atmospheric premixed flame under varying operating conditions. Proc ASME Turbo Expo 2010;2(PARTS A AND B):933-44. https:// doi.org/10.1115/GT2010-23135.

[7] Arias L, Torres S, Sbarbaro D, Ngendakumana P. On the spectral bands measurements for combustion monitoring. Combust Flame 2011;158(3):423-33. https://doi.org/10.1016/ j.combustflame.2010.09.018.

[8] Toro N C, Arias P L, Torres S, Sbarbaro D. Flame spectratemperature estimation based on a color imaging camera and a spectral reconstruction technique. Appl Optic 2014;53(28):6351. https://doi.org/10.1364/ao.53.006351.

[9] González-Cencerrado A, Peña B, Gil A. Coal flame characterization by means of digital image processing in a semi-industrial scale PF swirl burner. Appl Energy 2012;94:375-84. https://doi.org/10.1016/ j.apenergy.2012.01.059.

[10] González-Cencerrado A, Gil A, Peña B. Characterization of PF flames under different swirl conditions based on visualization systems. Fuel 2013;113:798-809. https:// doi.org/10.1016/j.fuel.2013.05.077.

[11] Huang HW, Zhang Y. Imaging based chemiluminescence characterisation of partially premixed syngas flames through DFCD technique. Int J Hydrogen Energy 2013;38(11):4839-47. https://doi.org/10.1016/ j.ijhydene.2013.01.142.

[12] Migliorini F, Maffi S, De Iuliis S, Zizak G. Analysis of chemiluminescence measurements by grey-scale ICCD and colour digital cameras. Meas Sci Technol 2014;25(5):055202. https://doi.org/10.1088/0957-0233/25/5/055202.

[13] González-Cencerrado A, Peña B, Gil A. Experimental analysis of biomass co-firing flames in a pulverized fuel swirl burner using a CCD based visualization system. Fuel Process Technol 2015;130(C):299-310. https://doi.org/10.1016/ j.fuproc.2014.10.041.

[14] Alviso D, Mendieta M, Molina J, Rolón JC. Flame imaging reconstruction method using high resolution spectral data of $\mathrm{OH}^{*}, \mathrm{CH}^{*}$ and $\mathrm{C2} *$ radicals. Int J Therm Sci 2017;121:228-36. https://doi.org/10.1016/j.ijthermalsci.2017.07.019.

[15] Guiberti TF, Durox D, Schuller T. Flame chemiluminescence from CO2- and N2-diluted laminar CH4/air premixed flames.
[17] Lauer M, Zellhuber M, Sattelmayer T, Aul CJ. Determination of the heat release distribution in turbulent flames by a model based correction of $\mathrm{OH}^{*}$ chemiluminescence. Proceedings of the ASME turbo expo, vol. 2. ASMEDC; 2011. p. 105-15. https://doi.org/10.1115/GT2011-45105.

[18] Giassi D, Cao S, Bennett BAV, Stocker DP, Takahashi F, Smooke MD, Long MB. Analysis of $\mathrm{CH}^{*}$ concentration and flame heat release rate in laminar coflow diffusion flames under microgravity and normal gravity. Combust Flame 2016;167:198-206. https://doi.org/10.1016/ j.combustflame.2016.02.012.

[19] Docquier N, Lacas F, Candel S. Closed-loop equivalence ratio control of premixed combustors using spectrally resolved chemiluminescence measurements. Proc Combust Inst 2002;29(1):139-45. https://doi.org/10.1016/S1540-7489(02) 80022-0.

[20] Muruganandam TM, Kim BH, Morrell MR, Nori V, Patel M, Romig BW, Seitzman JM. Optical equivalence ratio sensors for gas turbine combustors. Proc Combust Inst 2005;30(1):1601-9. https://doi.org/10.1016/j.proci.2004.08.247.

[21] Jeong YK, Jeon CH, Chang YJ. Evaluation of the equivalence ratio of the reacting mixture using intensity ratio of chemiluminescence in laminar partially premixed CH4-air flames. Exp Therm Fluid Sci 2006;30(7):663-73. https:// doi.org/10.1016/j.expthermflusci.2006.01.005.

[22] Keyvan S, Rossow R, Romero C, Li X. Comparison between visible and near-IR flame spectra from natural gas-fired furnace for blackbody temperature measurements. Fuel 2004;83(9):1175-81. https://doi.org/10.1016/j.fuel.2003.12.002.

[23] Lapalme D, Seers P. Influence of $\mathrm{CO} 2, \mathrm{CH} 4$, and initial temperature on $\mathrm{H} 2 / \mathrm{CO}$ laminar flame speed. Int J Hydrogen Energy 2014;39(7):3477-86. https://doi.org/10.1016/ j.ijhydene.2013.12.109.

[24] Lyu Y, Qiu P, Liu L, Yang C, Sun S. Effects of steam dilution on laminar flame speeds of $\mathrm{H} 2 /$ air/H2O mixtures at atmospheric and elevated pressures. Int J Hydrogen Energy 2018;43(15):7538-49. https://doi.org/10.1016/ j.ijhydene.2018.02.065.

[25] Wang F, Wang XJ, Ma ZY, Yan JH, Chi Y, Wei CY, Ni MJ, Cen KF. The research on the estimation for the NOx emissive concentration of the pulverized coal boiler by the flame image processing technique. Fuel 2002;81(16):2113-20. https://doi.org/10.1016/S0016-2361(02)00145-X.

[26] Joo S, Yoon J, Kim J, Lee M, Yoon Y. NOx emissions characteristics of the partially premixed combustion of $\mathrm{H} 2 /$ $\mathrm{CO} / \mathrm{CH} 4$ syngas using artificial neural networks. Appl Therm Eng 2015;80(x):436-44. https://doi.org/10.1016/ j.applthermaleng.2015.01.057.

[27] Kim N, Lee MC. Development of NOx response model of H2/ $\mathrm{CO} / \mathrm{CH} 4$ syngases with nitrogen dilution in a gas turbine model combustor. Int J Hydrogen Energy 2016;41(35):15834-40. https://doi.org/10.1016/ j.ijhydene.2016.04.130.

[28] Kim HS, Arghode VK, Gupta AK. Flame characteristics of hydrogen-enriched methane-air premixed swirling flames. Int J Hydrogen Energy 2009;34(2):1063-73. https://doi.org/ 10.1016/j.ijhydene.2008.10.035.

[29] Arrieta CE, García AM, Amell AA. Experimental study of the combustion of natural gas and high-hydrogen content syngases in a radiant porous media burner. Int J Hydrogen Energy 2017;42(17):12669-80. https://doi.org/10.1016/ j.ijhydene.2017.03.078. 
[30] Patel V, Shah R. Effect of hydrogen enrichment on combustion characteristics of methane swirling and nonswirling inverse diffusion flame. Int J Hydrogen Energy 2019;44(52):28316-29. https://doi.org/10.1016/ j.ijhydene.2019.09.076.

[31] Kalogirou SA. Artificial intelligence for the modeling and control of combustion processes: a review. Prog Energy Combust Sci 2003;29(6):515-66. https://doi.org/10.1016/ S0360-1285(03)00058-3.

[32] Li N, Lu G, Li X, Yan Y. Prediction of NOx emissions from a biomass fired combustion process based on flame radical imaging and deep learning techniques. Combust Sci Technol 2016;188(2):233-46. https://doi.org/10.1080/ 00102202.2015.1102905.

[33] Tóth P, Garami A, Csordás B. Image-based deep neural network prediction of the heat output of a step-grate biomass boiler. Appl Energy 2017;200:155-69. https://doi.org/ 10.1016/j.apenergy.2017.05.080.

[34] Han Z, Hossain MM, Wang Y, Li J, Xu C. Combustion stability monitoring through flame imaging and stacked sparse autoencoder based deep neural network. Appl Energy 2020;259:114159. https://doi.org/10.1016/ j.apenergy.2019.114159.

[35] Muruganandam TM, Nair S, Scarborough D, Neumeier Y, Jagoda J, Lieuwen T, Seitzman J, Zinn B. Active control of lean blowout for turbine engine combustors. J Propul Power 2005;21(5):807-14. https://doi.org/10.2514/1.7254.

[36] Li X, Sun D, Lu G, Krabicka J, Yan Y. Prediction of NOx emissions throughflame radical imaging and neural network based soft computing. In: 2012 IEEE international conference on imaging systems and techniques proceedings. IEEE; 2012. p. 502-5. https://doi.org/10.1109/IST.2012.6295594.

[37] Ruão M, Costa M, Carvalho M. A NOx diagnostic system based on a spectral ultraviolet/visible imaging device. Fuel 1999;78(11):1283-92. https://doi.org/10.1016/S0016-2361(99) 00037-X.

[38] Naha S, Aggarwal SK. Fuel effects on NOx emissions in partially premixed flames. Combust Flame 2004;139(1-2):90-105. https://doi.org/10.1016/j.combustflame.2004.07.006.

[39] Burbano HJ, Amell AA, García JM. Effects of hydrogen addition to methane on the flame structure and $\mathrm{CO}$ emissions in atmospheric burners. Int J Hydrogen Energy 2008;33(13):3410-5. https://doi.org/10.1016/j.ijhydene.2008.04.020.

[40] de Vries H, Mokhov AV, Levinsky HB. The impact of natural gas/hydrogen mixtures on the performance of end-use equipment: interchangeability analysis for domestic appliances. Appl Energy 2017;208(May):1007-19. https:// doi.org/10.1016/j.apenergy.2017.09.049.

[41] Zhao Y, McDonell V, Samuelsen S. Influence of hydrogen addition to pipeline natural gas on the combustion performance of a cooktop burner. Int J Hydrogen Energy 2019;44(23):12239-53. https://doi.org/10.1016/ j.ijhydene.2019.03.100.

[42] Zhao Y, McDonell V, Samuelsen S. Experimental assessment of the combustion performance of an oven burner operated on pipeline natural gas mixed with hydrogen. Int J Hydrogen Energy 2019;44(47):26049-62. https://doi.org/10.1016/ j.ijhydene.2019.08.011.

[43] E. Standard EN 437:2018. Test gases - test pressures appliance categories, standard. Brussels: European Committee for Standardization; nov 2018.

[44] Jones HRN. The application of combustion principles to domestic gas burner design. Abingdon, UK: Taylor \& Francis; 1989. https://doi.org/10.4324/9780203473139. arXiv:arXiv:1011.1669v3.

[45] Aggarwal SK. Extinction of laminar partially premixed flames. Prog Energy Combust Sci 2009;35(6):528-70. https:// doi.org/10.1016/j.pecs.2009.04.003.
[46] Ilbas M, Crayford AP, Yilmaz I, Bowen PJ, Syred N. Laminarburning velocities of hydrogen-air and hydrogen-methaneair mixtures: an experimental study. Int J Hydrogen Energy 2006;31(12):1768-79. https://doi.org/10.1016/ j.ijhydene.2005.12.007.

[47] Zhang Y, Wu J, Ishizuka S. Hydrogen addition effect on laminar burning velocity, flame temperature and flame stability of a planar and a curved $\mathrm{CH} 4-\mathrm{H} 2$-air premixed flame. Int J Hydrogen Energy 2009;34(1):519-27. https:// doi.org/10.1016/j.ijhydene.2008.10.065.

[48] Hu E, Huang Z, He J, Jin C, Zheng J. Experimental and numerical study on laminar burning characteristics of premixed methanehydrogen-air flames. Int J Hydrogen Energy 2009;34(11):4876-88. https://doi.org/10.1016/j.ijhydene.2009.03.058.

[49] Hu G, Zhang S, Li QF, Pan XB, Liao SY, Wang HQ Yang C, Wei S. Experimental investigation on the effects of hydrogen addition on thermal characteristics of methane/air premixed flames. Fuel 2014;115:232-40. https://doi.org/10.1016/ j.fuel.2013.07.024.

[50] Halter F, Chauveau C, Gökalp I. Characterization of the effects of hydrogen addition in premixed methane/air flames. Int J Hydrogen Energy 2007;32(13):2585-92. https:// doi.org/10.1016/j.ijhydene.2006.11.033.

[51] Chen Z, Qin C, Zhang Y. Flame stability of partially premixed combustion for PNG/LNG interchangeability. J Nat Gas Sci Eng 2014;21:467-73. https://doi.org/10.1016/ j.jngse.2014.09.018.

[52] Jones DR, Al-Masry WA, Dunnill CW. Hydrogen-enriched natural gas as a domestic fuel: an analysis based on flashback and blow-off limits for domestic natural gas appliances within the UK. Sustain Energy Fuel 2018;2(4):710-23. https:// doi.org/10.1039/c7se00598a.

[53] Hussain T, Talibi M, Balachandran R. Investigating the effect of local addition of hydrogen to acoustically excited ethylene and methane flames. Int J Hydrogen Energy 2019;44(21):11168-84. https://doi.org/10.1016/ j.ijhydene.2019.02.182.

[54] Reyes M, Tinaut FV, Giménez B, Pastor JV. Effect of hydrogen addition on the $\mathrm{OH}^{*}$ and $\mathrm{CH}^{*}$ chemiluminescence emissions of premixed combustion of methane-air mixtures. Int $\mathrm{J}$ Hydrogen Energy 2018;43(42):19778-91. https://doi.org/ 10.1016/j.ijhydene.2018.09.005.

[55] García-Armingol T, Ballester J. Flame chemiluminescence in premixed combustion of hydrogen-enriched fuels. Int $\mathrm{J}$ Hydrogen Energy 2014;39(21):11299-307. https://doi.org/ 10.1016/j.ijhydene.2014.05.109.

[56] Tripathi MM, Krishnan SR, Srinivasan KK, Yueh FY, Singh JP. Chemiluminescence-based multivariate sensing of local equivalence ratios in premixed atmospheric methane-air flames. Fuel 2012;93:684-91. https://doi.org/10.1016/ j.fuel.2011.08.038.

[57] Kojima J, Ikeda Y, Nakajima T. Spatially resolved measurement of $\mathrm{OH}^{*}, \mathrm{CH}^{*}$, and $\mathrm{C}^{*}$ chemiluminescence in the reaction zone of laminar methane/air premixed flames. Proc Combust Inst 2000;28(2):1757-64. https://doi.org/ 10.1016/S0082-0784(00)80577-9.

[58] Krabicka J, Lu G, Yan Y. Profiling and characterization of flame radicals by combining spectroscopic imaging and neural network techniques. IEEE Trans Instrument Measure 2011;60(5):1854-60. https://doi.org/10.1109/ TIM.2010.2102411.

[59] García-Armingol T, Ballester J. Influence of fuel composition on chemiluminescence emission in premixed flames of $\mathrm{CH} 4 /$ $\mathrm{CO} 2 / \mathrm{H} 2 / \mathrm{CO}$ blends. Int J Hydrogen Energy 2014;39(35):20255-65. https://doi.org/10.1016/ j.ijhydene.2014.10.039.

[60] Rocha N, Quintino FM, Fernandes EC. H2 enrichment impact on the chemiluminescence of biogas/air premixed flames. 
Int J Hydrogen Energy 2020;45(4):3233-50. https://doi.org/ 10.1016/j.ijhydene.2019.11.115.

[61] Pritchard R, Guy JJ, Connor NE. Handbook of industrial gas utilization : engineering principles and practice. New York: Van Nostrand Reinhold Co.; 1977.

[62] Namkhat A, Jugjai S. Primary air entrainment characteristics for a self-aspirating burner: model and experiments. Energy 2010;35(4):1701-8. https://doi.org/10.1016/ j.energy.2009.12.020.

[63] Prigg JA. Aerated burners. London \& Southern Junior Gas Association Meeting; 1955. p. 165-215.

[64] Shakil M, Elshafei M, Habib MA, Maleki FA. Soft sensor for NOx and $\mathrm{O} 2$ using dynamic neural networks. Comput Electr Eng 2009;35(4):578-86. https://doi.org/10.1016/ j.compeleceng.2008.08.007.

[65] Guo Y, Hastie T, Tibshirani R. Regularized linear discriminant analysis and its application in microarrays.
Biostatistics 2007;8(1):86-100. https://doi.org/10.1093/ biostatistics/kxj035.

[66] Levenberg K. A method for the solution of certain non-linear problems in least squares. Q Appl Math 1944;2(2):164-8. https://doi.org/10.1090/qam/10666.

[67] Marquardt DW. An algorithm for least-squares estimation of nonlinear parameters. J Soc Ind Appl Math 1963;11(2):431-41. https://doi.org/10.1137/0111030.

[68] Moré JJ. The Levenberg-Marquardt algorithm: implementation and theory. In: Lecture notes in mathematics. Springer Berlin Heidelberg; 1978. p. 105-16. https://doi.org/10.1007/bfb0067700.

[69] Hagan MT, Menhaj MB. Training feedforward networks with the marquardt algorithm. IEEE Trans Neural Network 1994;5(6):989-93. https://doi.org/10.1109/72.329697. 